\title{
HERNÁN NÚÑEZ ANTE EL TEXTO DEL LABERINTO: ELEMENTOS DE ECDÓTICA ANTIGUA Y HUMANÍSTICA*
}

\author{
Juan Casas Rigall \\ Universidade de Santiago de Compostela \\ juan.casas@usc.es
}

\section{La versión vulgata como texto base}

Como es notorio, el texto del Laberinto anotado por Hernán Núñez se basa en la edición sevillana de 1496 atribuida a Ungut y Polono, que a su vez seguía una estampa zaragozana de 1489. En último término, en lo que conocemos, la temprana tradición impresa se remonta al trabajo sine notis de hacia 1486 asignado al taller abierto por Diego Sánchez de Cantalapiedra y Alonso de Porras en Salamanca, que, salvo si hubiese alguna estampa previa perdida, constituye la edición príncipe del poema ${ }^{1}$.

Fue Bataillon quien defendió esta última hipótesis a partir del único ejemplar conocido en su tiempo y aún hoy en la Biblioteca Pública de Évora (inc.

${ }^{*}$ Este trabajo se enmarca en el proyecto de investigación «El comentario filológico hispánico entre los siglos XV y XVII» (PGC2018-096550-B-100) del Ministerio de Ciencia, Innovación y Universidades, dirigido por Antonio Azaustre Galiana, y en el grupo de referencia competitiva GI-1377 de la Xunta de Galicia (GRC 2019-2022 / ED431C 2019/03), dirigido por Santiago Fernández Mosquera.

${ }^{1}$ Para la filiación de los impresos, vid. M. Kerkhof, «Sobre las ediciones del Laberinto de Fortuna publicadas de 1481 a 1943 y la tradición manuscrita», en Forum litterarum, APA-Holland U. P., AmsterdamMaarssen, 1984, pp. 269-282; M. Kerkhof y R. Le Pair, «El Laberinto de Fortuna de Juan de Mena: las ediciones en relación con la tradición manuscrita», en Homenaje al profesor Antonio Vilanova, Barcelona, Universitat, 1989, vol. I, pp. 321-339; y M. Kerkhof (ed.), Juan de Mena, Laberinto de Fortuna, Madrid, Castalia, 1995, pp. 75-80 y 379-417. Sobre la producción de la princeps, vid. M. ${ }^{\mathrm{a}}$ A. Varona, «Identificación de la primera imprenta anónima salmantina», en Investigaciones históricas, 14 (1997), pp. 25-33, y J. Martín Abad, «La primera imprenta anónima salmantina (c. 1480-1494): últimos hallazgos y algunas precisiones», en Calligraphia et tipographia. Arithmetica et numerica. Chronologia, Barcelona, Universitat, 1998, pp. 437-458, p. 445, n. ${ }^{\circ} 10$. 
$464)^{2}$. Dado el origen salmantino de este impreso, el hispanista francés evaluó la posibilidad de que Nebrija hubiese supervisado de algún modo la edición, aunque su conclusión fue negativa: a su juicio, los espacios en blanco de la estampa, atinentes a voces y conceptos cultos, habrían sido resueltos por un humanista. Tal idea, sin embargo, fue refutada por Street, pues los propios textos nebrisenses presentan frecuentes erratas o lagunas, muestra de cierta desidia del gramático incluso a la hora de pulir sus impresos ${ }^{3}$.

Por añadidura, como argumenté en otro lugar, el único ejemplar de la plausible princeps oculta otra posibilidad: que haya habido diversos estados de edición con el texto del Laberinto corregido, o bien aquel mismo estado con banderillas o adiciones manuscritas para solución de los antedichos blancos. Puesto que el único testimonio de la princeps contiene fallas tan obvias, es natural que se hubiese planeado una refacción con las enmiendas oportunas $^{4}$. Y es posible que este proyecto de revisión se llevase a cabo en cierto grado. El cotejo de los seis lugares críticos defectuosos de la princeps con sus correlatos en las estampas de Zaragoza (1489) y Sevilla (1496), que evitan las lagunas, muestra la convivencia de conjeturas poco felices y lecturas correctas, indicio de que su ascendiente era ya distinto del estado del ejemplar evorense:

1. las áforas / los áforos gentes atán imperitas $(49 \mathrm{~g})$ los quales 14891496

2. El Cáucaso monte fue luego patente (50a) Caucabon monte 14891496

3. Getulia e Bisace, con más de otra tanta (50f) provincia 14891496

4. de aquella Cartago del bírseo muro (166b)

5. en Ras con aquel señor de Charní (199f)

6. e los que pigros en los sus oficios $(232 \mathrm{~g})^{5}$.

\footnotetext{
${ }^{2}$ Vid. M. Bataillon, «L'Édition princeps du Laberinto de Juan de Mena», en Estudios dedicados a Menéndez Pidal, Madrid, CSIC-Patronato Menéndez Pelayo, 1951, vol. II, pp. 325-334; traducido en Varia lección de clásicos españoles, Madrid, Gredos, 1964, pp. 9-20.

${ }^{3}$ Vid. F. Street, «Hernán Núñez and the Earliest Printed Editions of Mena's El Laberinto de Fortuna», en The Modern Language Review, 61 (1966), pp. 51-63. Los capítulos sobre vitia y licencias de la Gramática castellana son ejemplo de corrección de pruebas descuidada, no excepcional en Nebrija; vid. J. Casas Rigall, «Vicios gramaticales y licencias oratorias: un capítulo deturpado de la Gramática de Nebrija», en Neophilologus, 81 (1997), pp. 539-549, y Humanismo, gramática y poesía. Juan de Mena y los auctores en el canon de Nebrija, Santiago de Compostela, Universidade, 2010, p. 126.

${ }^{4}$ Vid. J. Casas Rigall, Humanismo..., pp. 125-127.

${ }^{5}$ En cada primera línea, el texto crítico del Laberinto sigue la citada edición de Kerkhof, de cuyo aparato proceden también las variantes de la tradición manuscrita y los impresos anteriores a 1499.
} 
En los casos 1 y 3, las lagunas de la princeps afectaban al gentilicio áforas-áforos, lecciones equipolentes (de Afri 'afros, africanos'), y al topónimo Bisace, formas cultas. Ya que la edición de Zaragoza -y, a su zaga, Sevilla- enmienda ope ingenii de manera pedestre, cabe suponer que su modelo mantenía la laguna, si no había introducido ya estas vulgares conjeturas. En cuanto a la enmienda del ejemplo 2, aunque no resulte del todo acertada, es similar a la lección de los manuscritos NH5 y SA5 (Caucabo monte). En contraste, los demás pasajes demuestran mayor tino en la resolución de los blancos del ejemplar de Évora, mediante los cultismos birseo (4) y pigros (6), y la alusión a un personaje coetáneo, el señor de Charní (5). Aquí no es posible dilucidar si las enmiendas sancionadas por las mejores lecciones manuscritas se incorporaron en el impreso de 1489, o figuraban ya en un estado corregido de la princeps del que no consta ejemplar. Esta última posibilidad no resulta inverosímil.

Con todo, incluso si así fuese, ni siquiera este proceso de lima bastaría para garantizar que el responsable filológico o inductor indubitado de la edición salmantina de hacia 1486 haya sido Antonio de Nebrija, lo cual tampoco se puede descartar de raíz. Weiss y Cortijo se muestran proclives a admitir tal hipótesis, e incluso aventuran que la alusión de Núñez en 1499 a «algunos hombres de grave doctrina y saber» (Prólogo, f. 3r) desalentados ante los problemas textuales del poema pudiera entrañar una referencia a las lagunas que acabamos de revisar ${ }^{6}$. Como fuere, Bataillon ponderó la prudencia del responsable del texto de la princeps, quien, en el estado del único ejemplar conservado, a falta de recurrir a la tradición manuscrita, al menos se abstiene de introducir conjeturas en el texto que le sirve de base ${ }^{7}$. Al margen del problema, es un hecho que Nebrija dio por buena la tradición de la princeps, pues se valió de ella para extraer los ejemplos del Laberinto en la Gramática castellana.

No es extraño, por ello, que la misma tradición sea aceptable para el joven Núñez como base de su texto del poema. Así, en los casos anteriores el Comendador Griego asume las lecturas de Zaragoza-Sevilla en los pasajes 3 a 6 -excepto el primero, de lección correcta a la luz de los manuscritos-. Y este es su fundamento incluso para el lugar crítico 2, aunque desde Caucabon monte proponga la conjetura Catabathmón, ajena a cualquier testimonio conocido (vid. infra). Con respecto al ejemplo 1, en contraste, cumple notar

${ }^{6}$ Vid. Hernán Núñez de Toledo, Glosa sobre las Trezientas del famoso poeta Juan de Mena, ed. de J. Weiss y A. Cortijo, Madrid, Polifemo, 2015, p. 58, edición y estudio monumentales que por fin hacen justicia al Laberinto del Pinciano. El mismo Núñez ilustra el uso de la laguna tipográfica provisional en la glosa sobre Macías de la copla 105 del Laberinto, en donde, como alegación de ignorancia, se deja en blanco el nombre del maestre de Calatrava, esto en 1499 y aún en 1505.

${ }^{7}$ Vid. Bataillon, art. cit., p. 329. 
cómo Núñez, que acogía la lección los quales en su edición de 1499 (Sevilla: Pegnitzer, Herbst y Glockner), en 1505 (Granada: Juan Varela de Salamanca) recurre a la tradición manuscrita para corregir los áforos, si bien silencia la procedencia de la lectura e implícitamente la presenta como enmienda ope ingenii -más abajo volveremos sobre esta cuestión-.

Ya que la princeps del Laberinto y sus derivaciones tempranas presentaban un texto aceptable, se podría pensar que Núñez se contentó con un punto de partida que lo eximía de la recensio de la tradición manuscrita. Sin embargo, su decisión, más que fundada en un juicio ponderado, sería más simple: al margen de la autoridad de la princeps, lo usual por el tiempo en las ediciones humanísticas es acogerse a la última estampa del texto que se va a publicar, constituido en versión vulgata hasta su reemplazado por una propuesta nueva. Los ejemplos son numerosos en Europa ${ }^{8}$. Antes de que la escuela de Poliziano estableciese la recensio como ideal y aun después, tal proceso no se concebía como tarea exhaustiva ni imprescindible. Incluso de admitirse, la recensio de tradiciones textuales de obras extensas con numerosos testimonios arredra al más pintado. Partir de una estampa previa, además de aligerar un cotejo laboriosísimo, resultaba también más práctico en la preparación de un libro impreso: el editor podía consignar sus enmiendas en los márgenes y la interlínea de un ejemplar previo sin necesidad de preparar un manuscrito íntegro, este restringido a las glosas, si hubiere; en cuanto al impresor, así se aplicaba a un modelo legible, sin los problemas paleográficos de una copia antigua, el cual de paso le servía como guía de composición tipográfica. Por otra parte, en una perspectiva académica, el referente de una edición previa permitía avivar el debate erudito en condiciones de igualdad: las distintas propuestas ecdóticas y hermenéuticas se difundían entre la comunidad humanística en espera de su recepción crítica, y cada edición se constituía en eslabón de una cadena.

Un caso común: a partir de la princeps, el stemma de las ediciones humanísticas traza una única rama vertical, en donde cada nueva estampa basa su texto en la precedente. La temprana tradición impresa del Laberinto ilustra perfectamente esta genealogía; y cuando en torno a 1582 el Brocense prepare una nueva edición del poema, partirá del texto glosado por Núñez en 1505,

\footnotetext{
${ }^{8}$ Sin salirnos de la bibliografía clásica, sobre el uso humanístico de la edición vulgata -etiqueta más común que textus receptus-, vid. S. Timpanaro, La genesi del metodo del Lachmann [1963], Padova, Liviano, 1981, pp. 3-4; L. Reynolds y N. Wilson, Copistas y filólogos [1968], Madrid, Gredos, 1974, pp. 269-271; E. Kenney, The Classical Text. Aspects of Editing in the Age of the Printed Book, Berkeley, University of California Press, 1974, pp. 4, 18-19 y 25-26; y A. Grafton, Joseph Scaliger. A Study in the History of Classical Scholarship. I. Textual Criticism and Exegesis, Oxford, Clarendon Press, 1983, pp. $14-15$
} 
con lo que la linealidad perdura. En la propia filiación del Laberinto de Núñez, por tanto, encontramos un primer eco de la edición humanística coetánea, el método censurado ya por Poliziano, quien como alternativa propugnaba la recensio sistemática de la tradición textual para determinar el testimonio de mayor autoridad, a su juicio necesariamente un manuscrito antiguo.

\section{Texto y emendationes}

\section{Anotaciones de crítica textual}

De acuerdo con el preciso catálogo de Weiss y Cortijo, Núñez dedica al Laberinto una cuarentena de anotaciones crítico-textuales en donde justifica su proceso editorial ${ }^{9}$. Dentro del mamotreto del Pinciano, en términos fríamente aritméticos tal proporción es exigua. Sin embargo, en la comentarística hispana del tiempo no hay ninguna aportación comparable: sin salirnos del ámbito meniano, en las tempranas glosas manuscritas del Laberinto la anotación de carácter textual brilla por su ausencia ${ }^{10}$. Este hecho conduce a Weiss y Cortijo a ponderar este estrato de anotación como un «hilo conductor» del comentario de Núñez, que, contra la apreciación tradicional, no debe ser evaluado «de espaldas a los criterios de su época» ${ }^{11}$.

En este sentido, si consideramos la práctica del humanismo coetáneo, la aproximación de Núñez se funda en el método tradicional del comentario al modo de Filippo Beroaldo el Viejo, maestro directo del Comendador en su primera estancia italiana, antes que en los nuevos rumbos de la Miscellanea de Poliziano (1489) o las Castigationes a Plinio de Ermolao Barbaro (14921493), en donde el primer objetivo es el apunte textual ${ }^{12}$.

El enfoque de Beroaldo ponía el acento sobre la exégesis frente a la crítica del texto, en particular limitada en cuanto al examen de manuscritos. Así, su edición comentada de Propercio (1486-1487) se basa en dos estampas previas -la princeps (1472) y la edición de Antonio Volsco (1482)-, así como en las enmiendas propuestas en el breve comentario de Domizio Calderini (1475). Con este fundamento, Beroaldo evalúa las variantes resultantes del cotejo sin apenas considerar las fuentes manuscritas; para colmo, cuando se

\footnotetext{
${ }^{9}$ Vid. Weiss y Cortijo, ed. cit., pp. 1018-1029.

${ }^{10} \mathrm{Vid}$. J. Casas Rigall, Juan de Mena y el Laberinto comentado: tempranas glosas manuscritas (c. 1444-1479), Salamanca, Ediciones Universidad, 2016, pp. 85-114.

${ }^{11}$ Vid. Weiss y Cortijo, ed. cit., p. 62.

${ }^{12}$ Sobre la biografía de Núñez, además de Weiss y Cortijo, ed. cit., pp. 15-20, vid. J. Signes, C. Codoñer y A. Domingo, Biblioteca y epistolario de Hernán Núñez de Guzmán (el Pinciano). Una aproximación al humanismo español del siglo XVI, Madrid, CSIC, 2001, pp. 1-13 y 226-242.
} 
apoya en estas, sus enmiendas ope codicum suelen estar erradas, porque, ajeno a una mínima recensio, no ha establecido el grado de la autoridad de los testigos. Antes bien, lo habitual en el Propercio de Beroaldo son las enmiendas conjeturales, a menudo fundadas sobre criterios paleográficos, de las que se tiende a hacer alarde en el comentario ${ }^{13}$.

Por esta atención escasa y defectuosa a la tradición manuscrita, Beroaldo será objeto de censura por parte de Poliziano, en cuya Miscellanea ni siquiera figura expreso el nombre del maestro boloñés -más abajo volveremos sobre el trasfondo de este silencio interesado-. Tal ocurre en la centuria prima, pese a que Poliziano parece inspirar su discurso en algunas propuestas textuales de Beroaldo ${ }^{14}$. El silencio se mantiene en la centuria secunda, inédita en su tiempo, en donde la referencia a un «alius» a propósito de la lectura paederastia en Suetonio, cuya supuesta documentación antigua niega Poliziano, evita la mención de Beroaldo incluso para su descrédito ${ }^{15}$. Por lo que respecta a Barbaro, en las Castigationes Plinianae se había mostrado igualmente cicatero con Beroaldo y sus Annotationes a la Naturalis historia (1476) o las Annotationes centum (1488), pese a manejarlas ${ }^{16}$.

En cuanto a su estatus en el marco del comentario, los apuntes textuales de Beroaldo y Núñez no se distinguen demasiado de las notas correlativas de Servio a los versos de Virgilio ${ }^{17}$. Y es natural, porque la recuperación humanística de la cultura clásica incluyó como piedra angular la gramática, en donde se integra la tradición comentarística antigua. En particular, Zetzel ha estudiado los elementos de crítica textual en las letras latinas, que, desde la

\footnotetext{
${ }^{13}$ Previamente el propio Beroaldo había cultivado el comentario selectivo atenido a problemas textuales en sus Annotationes a Plinio (1476), en donde, eso sí, priorizaba la enmienda conjetural (vid. infra); pero después de las Annotationes centum (1488) abandonaría este camino para ceñirse al comentario más tradicional. Vid. M. ${ }^{\text {a }}$ T. Casella, «Il metodo dei commentatori umanistici esemplato sul Beroaldo», en Studi medievali, 16 (1975), pp. 627-701, pp. 635-645; y J. H. Gaisser, «From Giovanni Pontano to Pierio Valeriano: Five Renaissance Commentators on Latin Erotic Poetry», en Classical Commentaries. Explorations in a Scholarly Genre, ed. de C. Kraus y C. Stray, Oxford, University Press, 2016, pp. 275298, pp. 285-290. Sobre el conjunto de su obra, vid. A. Severi, Filippo Beroaldo il Vecchio, un maestro per l'Europa, Bologna, Il Mulino, 2015.

${ }^{14}$ Vid. Casella, art. cit., p. 684.

${ }^{15} \mathrm{Vid}$. Angelo Poliziano, Miscellaneorum centuria secunda, $§ 20$; ed. de V. Branca y M. Pastore Stocchi, Firenze, Olschki, 1978 [1972], p. 30. Con todo, la actitud de Poliziano hacia Beroaldo se iría atemperando con el tiempo (vid. Filippo Beroaldo, Annotationes centum, ed. de L. Ciapponi, Binghamton, Medieval \& Renaissance Texts \& Studies, pp. 15-28), por lo que acaso este silenciamiento tardío sea más paternalista que displicente.

${ }^{16}$ Vid. Hermolai Barbari Castigationes Plinianae et in Pomponium Melam, ed. de G. Pozzi, Padova, Antenore, 1973, vol. I, pp. cxii, cxxv-cxxvi y cxxxiv-cxxxv.

${ }^{17}$ Sobre la concepción global del comento y el modelo serviano, vid. C. Codoñer, «El comentario de Hernán Núñez a las Trescientas de Juan de Mena. Un comentario del siglo XV», en Humanismo y pervivencia del mundo clásico. IV. Homenaje al profesor Antonio Prieto, ed. de J. M. ${ }^{a}$ Maestre et al., AlcañizMadrid, Instituto de Estudios Humanísticos-CSIC, 2008, vol. II, pp. 615-639.
} 
paupérrima desatención manifiesta en época republicana, progresa paulatinamente durante el imperio y en la Antigüedad tardía ofrece sus más interesantes muestras gracias a los gramáticos, en especial los escoliastas ${ }^{18}$. En este dominio destacan justamente los comentarios virgilianos atribuidos a Servio, en realidad una refundición de comentos previos con la aportación personal del gramático ${ }^{19}$. En conjunto, la crítica textual no es uno de los mayores intereses de Servio: de los 320 lugares críticos conflictivos de su corpus virgiliano, según estimación del citado Zetzel, solo se evalúa un tercio. Las variantes examinadas provienen de los escoliastas precedentes antes que de la consulta directa de manuscritos. Y cuando Servio se enfrente a un pasaje oscuro con aire deturpado sin lecciones alternativas en los comentos que refunde, tiende a aceptar la lectura insólita por más que le resulte forzada. En todo caso, en una perspectiva histórica, las anotaciones servianas sobre crítica textual tienen notable valor, y, muy difundidas, sin duda fueron un modelo para los primeros humanistas aplicados a la edición y el comentario, Núñez incluido.

\section{El lugar de la enmienda: ¿texto o glosa?}

La tradición filológica latina también es referente imprescindible para examinar esta cuestión: si el comentarista propone una enmienda, ¿debe consignarla en el texto o presentarla solo en nota? El problema se complica al concurrir un tercer elemento, el lema de remisión, esto es, la palabra o frase de la obra citadas como encabezamiento de la anotación para establecer la correspondencia entre texto y glosa. Porque en la práctica antigua y humanística con frecuencia se manifiestan discrepancias entre dos o incluso los tres formantes.

Una circunstancia material condiciona el contexto de la emendatio en los comentarios grecolatinos, que normalmente eran obras exentas, sin la compañía del texto analizado. Así, las propuestas de enmienda no tenían más ámbito que los paratextos autónomos; e incluso aquí había margen para el dilema, porque las variantes consideradas en la glosa contrastaban con la lectura del lema de remisión, no siempre coherente con la lección defendida. Esto ocurre a menudo en el comentario de Servio, que basa sus lemmata en un testigo virgiliano cuya lectura es refutada por otra variante preferible sin que se opere la corrección sugerida. En líneas generales, los gramáticos

${ }^{18}$ Vid. J. Zetzel, Latin Textual Criticism in Antiquity, Salem (New Hampshire), Monographs in Classical Studies, 1981, pp. 81-147.

${ }^{19}$ Vid. J. Zetzel, Critics, Compilers and Commentators. An Introduction to Roman Philology (200 $B C E-800$ CE), Oxford, University Press, 2018, pp. 262-263 y 319-321. 
se mostraban renuentes a enmendar el texto comentado. En contraste, en la Antigüedad tardía fueron comunes las subscripciones en donde el firmante declara haber revisado y enmendado el texto. Pero tales agentes no eran filólogos profesionales, sino lectores diletantes cuya tarea se limitaba a una lima superficial de la copia, ceñida a un cotejo con el modelo en busca de errores mecánicos, raras veces una recensio siquiera rudimentaria. En el dominio erudito, el proceso mediante el cual la enmienda pasa del comentario a los márgenes del texto, y de estos al texto en sí, es extraordinariamente lento, y todavía no se está consolidado entre los humanistas ${ }^{20}$.

Unas dos décadas después de la muerte de su padre, cuando los hijos de Nebrija deciden estampar un comentario virgiliano inédito del gramático (Granada, 1545-1546), lo hermanan a un texto divergente respecto de los lemmata y las lecturas de la glosa ${ }^{21}$. Hoy tendemos a justificar este híbrido por su carácter póstumo; sin embargo, por el tiempo no se vería como pastiche. Por caso, la edición de Juvenal por Giorgio Valla (1485 y 1495) mostraba este mismo uso. Y Beroaldo ilustra de nuevo la práctica que conduce a las discrepancias internas: en sus ediciones comentadas, las lecturas de texto, glosa y lema no siempre coinciden. De aquí se deriva que la ubicación de las enmiendas textuales ora en el cuerpo del texto, ora en la nota, no se consideraba cuestión relevante. En contraste, de manera excepcional, Barbaro se muestra extraordinariamente pulcro al discriminar los estratos de texto y glosa en la propuesta de enmiendas, que, de acuerdo con su método, se consignarán en los escolios, nunca en el texto.

En tal circunstancia se entiende el uso fluctuante del Laberinto de Núñez, cuyas enmiendas se sitúan en ocasiones en el cuerpo del poema, pero otras veces permanecen en la glosa sin que siempre medie el mayor o menor grado de fiabilidad de la propuesta como justificante claro. En esto, no obstante, entre las ediciones de 1499 y 1505 se producen transformaciones de interés ${ }^{22}$.

\footnotetext{
${ }^{20} \mathrm{Vid}$. Reynolds y Wilson, ob. cit., pp. 26-27; G. Morocho, «La transmisión de los textos y la crítica textual en la Antigüedad (I)», en Anales de la Universidad de Murcia, 38 (1979-1980), pp. 3-27, recogido en Estudios de crítica textual (1979-1986), Murcia, Universidad, 2004, pp. 5-32, pp. 21-28; y Zetzel, Latin Textual..., pp. 206-251.

${ }^{21}$ Vid. J. M. Díaz de Bustamante, «Nota a los prolegómenos del Virgilio de Nebrija», en Anuario de Letras, 31 (1993), pp. 121-133.

${ }^{22}$ En este apartado y los siguientes, buena parte de los lugares críticos han sido previamente evaluados por Kerkhof, ed. cit.; A. Alonso, «Comentando a Juan de Mena: Hernán Núñez y los humanistas italianos», en Il Confronto Letterario, 37 (2002), pp. 7-18; C. Codoñer, «Dos versiones de un comentario. La Glosa de Hernán Nuñez (el Pinciano) a las Trezientas de Juan de Mena», en A Greek Man in the Iberian Street. Papers in Linguistics and Epigraphy in Honour of Javier de Hoz, ed. de E. Luján y J. L. García, Innsbruck, Universität, 2011, pp. 337-354, y en especial Weiss y Cortijo, ed. cit., pp. 51-74, cada cual al hilo de sus hipótesis y argumentos.
} 
En algunos casos, la prudencia guía a Núñez, que advierte una probable deturpación pero, por no saber resolverla, se contenta con anotar la lectura conservadora. Así, en la relación de las sibilas, la tradición impresa incluye a una oscura Dimeta (121e) que suscita el recelo. En 1499 Núñez mantiene la lección extraña en el texto, pero propone alternativa en la nota:

Con la Dimeta. Ninguna de las diez sibillas hallo que se aya llamado Dimeta, segund de lo que arriba de ellas he relatado pudistes notar. Por ende pienso que se ha de emendar Cumeta, que es la quarta en la orden que antes contamos, la qual llama Lactancio Firmiano Cumea, y sancto Isidoro Cimeria. Esta fue de Italia, porque la que abaxo el auctor llama Cumea Lactancio no la llama sino Cumana, y Ausonio poeta en un epigrama «vincas Cumanam tu quoque Deiphobem», y Lucano «talis in Euboico vates Cumana recessu», y sancto Isidoro, donde trata de las sibillas, «dicta autem Cumana a civitate Cumis, etc. $\rangle^{23}$.

Sin embargo, el Pinciano no se sintió satisfecho con esta hipótesis, pues, en efecto, la Cumeta conjetural y la Cumea que versos después aparece en el Laberinto (122g) son a todas luces la misma sibila. Por ello, en 1505 optó por señalar la probable deturpación sin corregirla en el texto ni en la nota, esta más breve y expeditiva: «[...] pienso que se ha de emendar esta letra: el cómo por agora no me ocurre». Tampoco el Brocense sería capaz de aclarar el pasaje, ni los modernos editores de Mena, que mantienen la lección Dimeta, de modo que la segunda anotación de Núñez se demuestra atinada.

Otras veces, aunque Núñez se manifiesta más confiado, mantiene aún la lección vulgata en el texto y cede al lector la responsabilidad de admitir o no la conjetura. Tal recurso fue característico de su preceptor Beroaldo -así, en el Propercio o las Annotationes centum-, como útil didáctico que procura la participación activa del destinatario en la estela docente de san Jerónimo ${ }^{24}$. Por esta vía, en el verso 110c del Laberinto, entre los supuestos filtros de amor cuya eficacia la Providencia niega, están «las telas del hijo que pare la yegua», lectura uniforme en las tradiciones manuscrita e impresa. Sin embargo, Núñez, que mantiene la lección en su texto, conjetura una enmienda en la glosa, tanto en 1499 como en 1505 , y la plantea a sus lectores:

${ }^{23}$ Las citas del comentario de 1499 proceden del incunable 1.512 de la Biblioteca Nacional, con resolución de abreviaturas, puntuación y mayúsculas a la moderna, y unificación de alternancias de grafía no fonológicas. Para la revisión de 1505, sigo la citada edición de Weiss y Cortijo.

${ }^{24}$ Vid. Casella, art. cit., pp. 646, 648 y 650; y Ciapponi, ed. cit., p. 8. 
Las telas del hijo que pare la yegua. No me acuerdo aver leído en libro alguno que en las hechizerías usen las malas mugeres o hombres que las tales artes exercitan de las telas de los potricos que las yeguas paren, como aquí parece querer significar el auctor. Lo que leo es esto: que los potricos rezién nacidos tienen en la frente una carnezilla pequeña que llaman hippomanes, de quantidad de un higo, la qual les arrancan las madres en pariéndolos con la boca y la tragan; y si por caso la yegua halla el hijo sin aquella carnezilla, aborrécele y no le quiere criar. Esta carnezilla arrancan las malas mugeres para sus hechizerías. Auctores d'esto son Plinio, Vergilio, Ovidio y Aristóteles. Por ende no me parece que se deve leer telas, aunque en todos los libros que hasta agora han venido a mis manos se lea así, porque no haze nada al propósito en este lugar mención de las telas, salvo si dezimos que llama telas aquella carnezilla porque es sotil y pequeña, como Plinio y otros auctores comparen la carnezilla que nace a los ciervos en el mismo lugar que poco después han de nazer los cuernos a las telas de las cañas y al cuero sotil y seco, que semeja telas [...]. Pero considere el diligente lector si aquí por telas se deva emendar zelos, y que se entienda «los zelos del hijo que pare la yegua» por los amores, porque aquella carnezilla es causa del amor que las yeguas tienen a los hijos. D'este vocablo zelo por 'amor' usó ya el auctor en el principio: «aquel con quien Júpiter tuvo tal zelo» [1b] (glosa de 1499, con variantes ortográficas en 1505).

Núñez desconfía de la acepción biológica de telas, innecesariamente porque está bien documentada -sin ir más lejos, en las «telas del coraçón» del Cantar del Cid (v. 3260) ${ }^{25}$ - Pero la unanimidad de la tradición textual arredra al Comendador, que al menos busca justificación, forzada, en un supuesto uso figurado. Aun así, en la glosa no resiste la tentación de ofrecer al «diligente lector» la improcedente conjetura zelos.

Las estrofas 245-246 del Laberinto reciben un tratamiento parejo, pero aquí encontramos la más feliz divinatio de Núñez. En la tradición manuscrita y los impresos previos, la copla «Ya començava la invocación...», que describe los visajes descompuestos y voces horrísonas de la maga de Valladolid en un sortilegio de resurrección, aparece antes de la estrofa «E busca la maga ya fasta que falla...», en donde la hechicera se procuraba un cadáver insepulto para sus fines. El orden no es lógico, pues la localización del muerto debe ser necesariamente previa al conjuro, que consiste en la transmigración de un espíritu de poderes proféticos al cuerpo revivido. El Pinciano propone la inversión estrófica del orden común a todos los testimonios, una secuencia que, más propia en sí misma, también enlaza mejor con la estrofa 247 , en donde

${ }^{25}$ Vid. otros ejemplos en L. Kasten y F. Cody, Tentative Dictionary of Medieval Spanish [1946], HSMS, New York, 2001, s. v. tela, acepción 1. 
se refiere el conjuro en discurso directo; como apoyo, la fuente, un pasaje de la Farsalia (6, vv. 624 y ss.), sanciona la hipótesis de reordenación:

Ya començava la invocación. Esta copla con la siguiente pienso que fueron por ignorancia de los libreros falsamente trastocadas y la una puesta en el logar de la otra, como otras muchas cosas se leían en esta obra corrompidas y viciadas por no ser freqüentada de hombres doctos. La razón que me mueve a pensar esto es, lo uno, la orden del proceder, que primero se avía de buscar el cuerpo muerto y después ungirlo, y lo último hazer la invocación; y, lo otro, que Lucano, del qual tomó como muchas vezes he dicho Juan de Mena aquesta fictión, lleva esta misma orden que dezimos. D'esto juzgará el discreto letor como le ploguiere: básteme a mí aver demostrado el error [...] (glosa de 1499, con variantes menores en 1505).

Núñez repara con tino admirable en este probabilísimo error del arquetipo, y propone la inversión de coplas que los editores modernos suelen aceptar. Sin embargo, ni en 1499 ni en 1505 se decide a recomponer su texto del Laberinto.

En los casos anteriores, pues, al mantener sus propuestas de enmienda en la glosa al servicio del lector, Núñez parece actuar como los más pulcros editores humanistas de su tiempo, aunque, según hemos visto, este uso conservador es característico del comentarista antiguo. En contraste, las muestras que siguen presentan más bien al humanista que fija el texto pagado de su ingenium, lo cual se verifica más acusadamente en la segunda redacción del comentario. En estas correcciones manifiestas entre 1499 y 1505 no siempre se coordina el texto con la anotación, de ahí las inoportunas discrepancias.

El primer ejemplo es muy simple. A partir del verso «y las siete Pléiadas quien las otea» (8e) de 1499, en 1505 Núñez introduce la conjetura «en ellas otea». Sin embargo, el lema de remisión de la glosa aún mantiene la lectura incunable en la segunda edición, que no se actualiza de acuerdo con la enmienda de su texto. Esta falta de correspondencia, no inhabitual por el tiempo, se repetirá en otros pasajes. Al margen de ello, en el haber de Núñez está el advertir aquí una lectura de sintaxis forzada y escaso sentido en la tradición impresa anterior y los manuscritos $B C 3$ y $B M 1$. Pero su solución es una conjetura sin base en la tradición textual del Laberinto que, para colmo, ni siquiera es notada en la glosa.

El v. 109g presenta dos lugares críticos conflictivos, que reciben un tratamiento dispar en el comentario de 1505. En origen, en la línea de la princeps y sus primeros descendientes, en 1499 se lee «bulada devieran tener en la frente». La primera voz es objeto de esta anotación en la edición incunable: 
Bulada devieran tener en la frente [...]. 'Escrita en la frente', y declara la causa por que padecen para que diessen exemplo a otros que se apartassen del vicio en que ellos cayeron, por que evadiessen el tormento semejante. Bula, como escrive Sexto Pompeio, era una insignia de oro como joya que los hijos de los nobles traían colgada de los pechos, a denotar que la tal edad se ha de regir por consejo de otro [...]. Pero que diremos que en el cerco primero de la Luna, tratando de la rueda de los pasados y de la rueda de los presentes y de la de los por venir, dixo, como vimos, «que debaxo de todas estava / caída por tierra la gente infinita / que avía en la frente cada qual escrita / el nombre y la suerte por donde passava» [56eh], y que los por venir tenían cubiertos sus motes con un velo túrbido, y los presentes y passados descubiertos, pues como estos de que aquí ha tratado sean pasados, ¿qué es la razón por que dize que devieran tener escrita en la frente la causa de la pena que padecían? Quasi quiera dezir que no la tenían, lo qual es contrario de lo que ha dicho. Por ventura diremos que por bulada se ha de leer borrada, que quiera dezir 'testada y raída', como cosa abominable y turpe, segund en otro lugar dirá d'esta misma manera de las guerras civiles del rey don Juan con los infantes: «Otros entalles no tanto bruñidos / con epitafios de títulos ciertos / vi cómo eran deletos y muertos, / unos testados y otros raídos» [154ad].

La argumentación es meritoria, pues se basa en el usus scribendi de Mena y la coherencia interna respecto de otros pasajes del Laberinto, la misma estrategia que Barbaro había empleado con cierta frecuencia en sus Castigationes Plinianae. De acuerdo con Núñez, la voz bulada 'escrita' es sospechosa de deturpación, porque con anterioridad la Providencia informaba acerca de las figuras humanas en las ruedas del tiempo, inscritos en su frente «el nombre e la suerte» (56g), esta en referencia al carácter virtuoso o vicioso, de lectura clara en las gentes pasadas y presentes, y confusa en las futuras. Si esto es así -arguye Núñez-, no tiene sentido la optación «bulada devieran tener en la frente / la pena que andan aquí padeciendo» (109gh). El error de su planteamiento radica en que bulada significa no 'escrita', sino en particular 'grabada a fuego' - esto ya en el Vocabulario español-latino de Nebrija (s. v. bular), una acepción que recoge aún el DRAE como desusada-. A decir de Mena, por tanto, los lujuriosos debieran llevar su pena no inscrita en su frente sin más, sino grabada a fuego. Así, la conjetura borrada, que Núñez solo apunta en nota, está de más.

El comentario de 1505, después de reiterar la glosa anterior sin variantes de relieve, añade una coda sobre frente, la palabra rima de ese mismo v. 109g: «Algunos dizen que se ha de leer en la mente, y que sea como consejo del poeta, lo qual me agrada». A diferencia del lugar previo, en este caso Núñez 
incorpora la enmienda a su texto del Laberinto, y esto seguramente porque es una corrección ope codicum, pues ese «algunos» es plausible referencia a la tradición manuscrita en donde se documenta la variante privilegiada $(B M 1$, $G B 1, H H 1, M L 2, M N 6 b$ y $P N 5)$. Si esto es así, Núñez está enfocando este lugar crítico a la manera de Barbaro o Poliziano. El caso es que, como se apreciaba al principio del mismo verso, el uso convive con la divinatio.

Una nueva prueba de esta querencia conjetural lo encontramos en el v. 259a, a propósito del camaleón y su dieta. En 1499 «Al gamalión que en el aire se cría» da pie a una glosa en que se pone en duda la rección preposicional, con una alternativa:

Al gamalión que en el aire se cría. El animal gamalión, como escrive Plinio en el octavo libro de la Natural historia, es un animal que se cría en África y en la India, de figura y grandeza de una lagartixa, sino que tiene las piernas derechas y mayores [...]. Asimismo Alberto Magno y otros auctores hazen mención d'él. Ovidio en el último libro del Metamorfoseos: «Id quoque quod ventis animal nurritur et aura protinus assimilat tetigit quoscumque colores»; quiere dezir: 'Y el animal que se cría o mantiene del aire y de los vientos luego assemeja qualquier color que toca'. Por las quales palabras de Ovidio podrá claramente ver el diligente letor que se ha de emendar en esta copla «Al gamalión que del aire se cría», no «Al gamalión que en el aire se cría», como hasta agora corruptamente se leía. Porque falso es dezir que este animal se cría en el aire, porque no se cría sino en la tierra, que si en el aire se criasse, ¿cómo tocaría en la tierra las colores que semeja y cómo sería verdad lo que dize Plinio, que cerca de los cabrahigos es cruel y en los otros logares manso, y que en el invierno se asconde como las lagartixas? Así que no se ha de leer «en el aire se cría», sino «del aire se cría», quiere dezir, que se govierna solamente del aire sin otro manjar alguno. Y d'esto, porque es muy claro, no más [...].

La glosa de 1505 es la misma, con la cita de Ovidio solo en romance. Pero, frente a la primera edición, en donde la conjetura permanecía en la glosa, ahora la variante se consigna en el texto del Laberinto, aunque no se cambie el lema como convendría. La argumentación de Núñez, que se declara rotundamente persuadido de la fiabilidad de su hipótesis, no carece de lógica: el camaleón, de acuerdo con la tradición animalística, es animal telúrico y no aéreo, que, según la creencia antigua, se alimenta de aire. Ahora bien, si bien la interpretación de «en el aire» como 'mediante el aire' parece de sintaxis y sentido demasiado forzados incluso para Mena, que los naturalistas hayan explicado la portentosa dieta del camaleón no presupone que el poeta haya comprendido cabalmente el detalle. Y el hecho es que toda la tradición textual 
del Laberinto concurre en la lección en el aire, que mayoritariamente mantienen los editores modernos. En cualquier caso, la tajante seguridad de Núñez en su propuesta no lo indujo a presentar su enmienda en el texto hasta 1505.

En términos actuales, la localización de la conjetura en el cuerpo del poema con la oportuna indicación resulta natural, pero, en su tiempo y aun antiguamente, no todos los editores aplaudían esta clase de intervenciones. En general, en los últimos ejemplos examinados el Núñez de 1499 se mostraba más prudente en la enmienda de la vulgata, con sus conjeturas ceñidas a la glosa. En 1505, en cambio, eleva algunas divinationes al texto, pero sin criterio uniforme: borrada como corrección de bulada, pese a la prolija argumentación de la nota, permanece en el comentario, y lo mismo ocurre con zelos por telas, pero sobre todo destaca que la brillante inversión de las coplas 245246, la conjetura más convincente de toda la edición de Núñez, no alcance el estrato del texto. Por otra parte, que en el mismo verso, tras la conservación de bulada, el Comendador decida mudar frente por mente demuestra una cesión ante la autoridad de los manuscritos. Según veremos, no es este un proceso insólito en su edición, especialmente su redacción definitiva, pero, a diferencia de este ejemplo, la glosa de Núñez no siempre declara sus enmiendas. Así y todo, no son de extrañar estas vacilaciones editoriales en un humanista del cambio de siglo.

\section{«Emendatio ope ingenii» y anotación filológica}

En el conjunto de enmiendas de Núñez con glosa anexa, la argumentación echa el resto en las correcciones sin apoyo en la tradición textual. El proceso, por una parte lógico, revela también el gusto humanístico por el alarde de ingenium, pues, a fin de cuentas, el recurso a los manuscritos demostraba esfuerzo, pero no sutileza erudita. En líneas generales, desde la Antigüedad hasta el s. XVIII, tal será la actitud dominante en la edición de textos. En esto, estudiosos como Barbaro, Poliziano y su escuela serán temprana excepción.

Aunque ya Bataillon censuró «une ingeniosité parfois redoutable dans la conjecture» en el Pinciano ${ }^{26}$, en ocasiones este intenta poner coto a los desmanes hipotéticos: ya por conocer el planteamiento defensor la variante atestiguada, ya por la reflexión desde su propia práctica editorial o por la esperable combinación de ambos factores, Núñez es consciente de los peligros de la divinatio. Otra cosa es que finalmente logre sustraerse al orgullo intelectual que esta clase de enmiendas provee.

${ }^{26}$ Vid. Bataillon, art. cit., p. 331. 
Especialmente revelador es el comentario sobre el mago nombrado en el v. 130b del Laberinto, lección que en 1499 recibe un tratamiento bastante conservador:

Vimos la forma del mago Tireo. Tireo pone por Tiresias, corrompido el vocablo por dar lugar al consonante, como he dicho que muchas vezes suele hazer en esta obra Juan de Mena por licencia poética. Fue Tiresias, como dize Homero en el décimo libro de la Odissea, natural de la cibdad de Thebas y hijo de Peritro, como Lactancio grammático nota sobre la Thebaida de Stacio [...]. Pero es aquí de ver por qué Juan de Mena nombra por mago a Tiresias, como quasi siempre se lea aver sido sacerdote y profeta más que mago, lo qual me acuerdo averme preguntado un varón de asaz doctrina y raríssima erudición en estos reinos. A esto se ha de responder que Tiresias fue lo uno y lo otro, propheta y mago, segund que d'él se lee en Stacio en el quarto de la Tebaida [...]. Así que de esto se collige que Tiresias fue mago y que no sin causa dize aquí el poeta «vimos la forma del mago Tireo». De otra manera se podría aquí leer para que se refiriese a otros magos, pero no nos plaze violentar el testo ni ser adevinos, «cum Delphis oracula cessent».

En un principio Núñez justifica la lectura Tireo como alusión a Tiresias. En realidad, aunque no se indique, la tradición impresa y buena parte de los códices leían Tereo, que Núñez muda levemente desde la raíz del nombre mitológico de referencia. Estas correcciones, de justificación paleográfica inmediata, son la clase de enmienda que, sin hacerse plenamente ope codicum, Poliziano y Barbaro tienden a aprobar, sobre todo a partir de un testimonio antiguo. Que Núñez, quien, según veremos, conocía bien algunas de sus obras, desaproveche la oportunidad de ilustrar el método, revela otros intereses teóricos. Sin embargo, la renuncia expresa a proponer conjeturas más osadas, subrayada por la irónica cita de Juvenal $(6,555)$ sobre el oráculo de Delfos, muestra al menos a un editor consciente de los potenciales excesos de la divinatio.

Por poco tiempo, pues en 1505 se incorpora a la glosa primitiva otro párrafo con nuevas consideraciones que conducen a la enmienda Thirreo. Tras añadir el Edipo de Sófocles para apuntalar la caracterización de Tireo-Tiresias como mago, Núñez entona la palinodia:

Pero nin por esto non me contenta esta sentencia, porque entre Tereo y Tiresias ay mucha diferencia. Pensando después en este passo, vine en creer que por Tereo se debe leer aquí Thyrreo, y que entiende Juan de Mena por Tages, el qual fue natural de Italia, de la provincia Thyrrenia [...], al qual Ovidio 
en el quinceno libro del Metamorfoseos llama Thyrreno, como aquí Juan de Mena quitó la $n$ por el consonante y dixo Thyrreo.

Y sigue la cita precisa de las Metamorfosis $(15,553-554)$, con breve comentario confirmatorio. Obsérvese cómo, por un momento, Núñez recupera la lección Tereo, de amplia documentación, pero, en el extremo opuesto, cede a la tentación de una conjetura atrevida que los editores actuales del Laberinto rechazan, y contradice su socarrona alusión previa a Delfos.

Otra de las enmiendas de que Núñez más se ufana contiene, no obstante, un matiz que en 1505 atenúa el orgullo del hallazgo de 1499. En los vv. 241 bc del Laberinto, las tradiciones manuscrita e impresa coinciden en la lectura en negrita: «de hiena non menos el nodo más tuerto, / después que formada d'espina de muerto». El Comendador, sin embargo, arriesga una interesante lectura conjetural:

Después que formada de espina de muerto. En estas palabras está un grand flagicio y error de los impressores que me tovo asaz días suspenso, los quales, por escrevir «de sierpe formada de espina de muerto», escribieron corruptíssima y viciosamente «después que formada de espina de muerto». Y este es uno de los logares muy difíciles que en esta obra sacamos nosotros primero a luz, lo qual sea dicho sin arrogancia [...] (glosa de 1499).

La argumentación subsiguiente de Núñez se ampara en Plinio, Servio y Plutarco, quienes autorizan la idea de la generación de serpientes en la médula humana. En consecuencia, aunque el lema mantenga la lección vulgata, se propone la enmienda «de sierpe formada de espina de muerto», que ya en 1499 se incorporaba al texto editado.

Pero en 1505 la ostentación se rebaja de forma sintomática: «Y este es uno de los logares difíciles que en esta obra avía». Núñez sigue ponderando la dificultad del pasaje, y es obvio que continúa satisfecho con una solución que mantiene; pero retira el subrayado «sacamos nosotros primero a luz», que de paso evita la subsiguiente y forzada fórmula de falsa modestia «sea dicho sin arrogancia». De este modo, el Pinciano se demuestra consciente del probable desagrado lector ante una prueba de erudición soberbiosa, una erudición que, limpia, no requiere mayor relieve. Por lo demás, esta divinatio tiene cierto predicamento entre los editores modernos -Blecua y Vasvari la aceptan-, aunque no sea la alternativa dominante ${ }^{27}$.

${ }^{27}$ Vid. Juan de Mena, Laberinto de Fortuna, ed. de J. M. Blecua, Madrid, Espasa-Calpe, 1943; y ed. de L. Vasvari, Madrid, Alhambra, 1976. Aunque De Nigris no acoja la conjetura de Núñez, considera confusa la lección común después que y anota cómo «Hernán Núñez la enmendó, muy felizmente, en de 
Como en los ejemplos anteriores, en general las conjeturas detalladas de Núñez constan de un aparato de concordancias clásicas. Es lógico que estas citas y referencias alarguen el discurso, pero en la amplificatio formal está inherente la amplificación del mérito del sabio comentarista. Según hemos comprobado, cuando el criterio que funda la enmienda pasa a ser el usus scribendi o la coherencia interna del poema, la glosa puede alcanzar cierto desarrollo -revísense arriba los casos de bulada-borrada (v. 109g) o la inversión de las estrofas 245-246-. Sin embargo, dentro de esta categoría de conjeturas, en 1505 es relativamente frecuente la corrección sin nota aparejada:

1. sigue mi vía, ven, ven y sucede (26b) ven tú ven

2. ramo ninguno avrá menester (28h) non avrá

3. en la qual si hachas queriendo pro quemar

4. Debaxo de aquestos vi

$$
\text { yo vi }
$$

5. de bienes agenos golosa garganta (99f) robos notorios
1505

princeps 148914961499

PN7 et passim

1505

1499 et passim

1505

1499 et passim

1505

princeps 148914961499

PN7 et passim

1505

1499 et passim

En esta cala, frente a la lectura común a la tradición aceptada en 1499, en 1505 Núñez decide introducir un ligero reajuste conjetural que mejora el sensus del discurso. Así, en el ejemplo 3, en donde Mena se refería a la portentosa fuente de Epiro, cuyas aguas encienden las antorchas apagadas, la lección dominante parece extraña a primera vista («...si fachas queriendo quemar / muertas metieren, se encienden de fuego», 45ef), de donde la corrección provar. En realidad, la lectura documentada consuena perfectamente con el prodigio -los lugareños conocen la propiedad maravillosa del agua, por lo que sumergen antorchas para prenderlas-, si bien editores modernos como Foulché-Delbosc y Blecua admitieron la sutil divinatio de Núñez ${ }^{28}$. De modo análogo, en el lugar crítico 5 la referencia meniana a los afanes de la avaricia, metafóricamente una «golosa garganta», presenta el complemento «de robos notorios» en el resto de la tradición, que hace pleno sentido. Pero

sierpe» (vid. Juan de Mena, Laberinto de Fortuna y otros poemas, ed. de C. de Nigris, estudio de G. Serés, Barcelona, Crítica, 1994, p. 162 n.). Por su parte, Kerkhof, ed. cit., p. 225 n., entiende que Mena concibe la hiena como una variedad de serpiente, por lo que la lectura documentada es correcta.

${ }^{28}$ Vid. Juan de Mena, El laberinto de Fortuna, ed. de R. Foulché-Delbosc, Mâcon, Protat Fréres, 1904; y Blecua, ed. cit. 
en 1505 Núñez conjetura un objetivo más propio en la definición común del vicio, que integra la codicia (Laberinto, 98e), ansiosa «de bienes ajenos», corrección que otra vez contenta a Blecua. En los demás casos, la res metrica fundamenta de un modo u otro las enmiendas. En los pasajes 1 y 4, la tradición de la princeps presenta un verso corto que rompe el ritmo dactílico del verso de arte mayor. El pie métrico también falla en el ejemplo 2, aun siendo de lección unánime en la tradición restante, ahora por exceso silábico. Lo más probable es que el original de Mena presentase, en vez de non (avrá), la variante sincopada no, que se documenta en otros contextos del Laberinto (vv. 4a, 57a, 67b, 112f, 133c...) y aquí propiciaría una sinalefa conveniente para el dáctilo. Pero la solución de Núñez es ingeniosa: al lado de ninguno, el adverbio de negación es sintáctica y semánticamente prescindible, de ahí su eliminación conjetural.

En conjunto, el texto de 1505 nos muestra a un Núñez loablemente preocupado por depurar su texto del Laberinto. En los ejemplos revisados, aunque este proceso corrector sea conjetural, las enmiendas se apoyan en criterios objetivos como el sentido y la métrica. Falta, eso sí, la señalización de las manipulaciones del texto en la glosa, defecto inadmisible para Barbaro o Poliziano, pero común por el tiempo. Además, en los ejemplos 1 y 4 la tradición manuscrita del Laberinto proporcionaba otras soluciones, y si bien es cierto que desconocemos los códices precisos que Núñez manejó, la amplia documentación de aquellas variantes manuscritas revela a un editor demasiado confiado en la divinatio. En todo caso, aunque el Comendador no anotase estas enmiendas menores por considerarlas poco meritorias, el hecho mismo de reparar en su conveniencia entronca inesperadamente con el método que propugna la lectura atestiguada, pues esta también suele aparecer sin glosa declarante en el Laberinto.

\section{La «emendatio ope codicum» y los silencios del comentarista}

En el comentario de Núñez, en efecto, un velo análogo afecta a muchas enmiendas del texto del Laberinto a todas luces basadas en la tradición manuscrita. En el prólogo de 1499, el Pinciano declara haber reunido todos los testimonios de que ha sido capaz, para limpiar el poema de «muchos vicios y depravaciones que la crassa ignorancia de los libreros en él avía cometido, las quales, juntados con la mayor diligencia que pude muchos ejemplares, emendé y corregí» (f. 3r). Con todo, aunque sobre todo en 1505 habrá bastantes remisiones a testigos previos -marcada por la alusión a libros, libreros 
e impresores o mediante fórmulas como «algunos/otros dizen»-, Núñez no siempre revelará la naturaleza ope codicum de sus enmiendas.

Solo en casos aislados la nota de Núñez asume expresamente la variante documentada o, cuando menos, muestra su satisfacción con tal lectura:

toda la flota llevó de Messano (166d)

loó de más sano princeps 148914961499

PN7 et passim 1505

Assimismo [...], «Toda la flota llevó de Messano» yo entendí por la cibdad de Mecina. Agora digo que ay algunos que dizen que se deve emendar «toda la flota loó de más sano», de manera que quiera dezir que quando Eneas partió de Carthago en la grand tempestad que le tomó, la qual cuenta Vergilio en el principio del quinto de la Eneida, Eneas y toda su flota loó el voto o sentencia de Palinuro por sana y provechosa [...] (1499, «Al lector», f. 190r).

y los de los barcos levanten los remos (173b) princeps 1489149614991505 bancos PN7 et passim

$Y$ los de los barcos. Algunos dizen que no se ha de leer barcos, sino vancos, lo qual no me desagrada (glosa de 1499 y 1505).

En la primera muestra, en consonancia con el epílogo de 1499, el comentario y el texto de 1505 renuncian a la lectura de la tradición impresa frente a la enmienda defendida por «algunos que dizen», que, pese a la aparente remisión a lectores doctos del Laberinto, recurre directa o indirectamente a la tradición manuscrita, en donde «loó de más sano» es lección casi unánime. En el segundo ejemplo, Núñez apunta solo en nota una variante convincente, que no asciende al texto de 1499 ni 1505 . Como en el pasaje previo, el vago «algunos dizen»es plausible referencia a testimonios manuscritos ${ }^{29}$.

Otras veces el Comendador se limita a presentar la lectura manuscrita como alternativa admisible -o lección equipolente, en términos estemmáticos- sin sopesar expresamente la calidad de las variantes. Aunque su propia selección constituya una obvia declaración editorial, recuérdese que, según hemos comprobado, la lectura preferida por Núñez no siempre llega al texto ni siquiera en 1505, de ahí la ambigüedad:

que los africanos los hechos del Cid (4b) de Africano
NH5 1489149614991505 PN7 et passim

\footnotetext{
${ }^{29}$ En otros pasajes el referente de la fórmula resulta menos claro. Con prudencia advierten Weiss y Cortijo, ed. cit., pp. 63-65, el sentido dilógico de estas expresiones, pues en ciertos contextos -las glosas $12 \mathrm{e}$ o $46 \mathrm{~g}$ en 1505, por ejemplo- la falta de documentación de las variantes aducidas por «algunos» apunta a un indefinido en alusión a individuos, no a manuscritos, si bien también es posible que Núñez tuviese a su disposición códices actualmente desconocidos.
} 
Algunos dizen que se ha de leer en el texto «que los de Africano», y que se entienda por Scipión Africano el Mayor (glosa de 1505).

¡Oh ínclita Roma, si d'esta supieras (79e) princeps 1489149614991505 quírita PN7 LB2 quérita BC3 BM1 HH1 MM1 SM1 SV2 Algunos dizen que se ha de leer en esta copla «iOh quírita Roma!», y no ínclita (glosa de 1505).

De nuevo, la fórmula «algunos dizen» se emplea como alusión directa o indirecta a la lectura de los manuscritos. Y en ambos ejemplos estamos ante adiciones de 1505 .

En otras ocasiones, cuando falta una remisión expresa, Núñez parece presentar como conjeturas lecciones que, en realidad, están documentadas en la tradición manuscrita. Es posible que en algún caso el Pinciano llegue por poligénesis a una solución conjetural coincidente con una variante atestiguada, pues la puridad gramatical del discurso puede revelar la lectura correcta. Por ejemplo, en los versos «algunos de moros tenidos por buenos / lançan temblando las sus azagayas» (179ef), la princeps trabucó la forma verbal con un impropio lanças, que obviamente no concierta con el sujeto, error que aun así pasó a las ediciones de 1489 y 1496. La lección correcta figuraba en casi toda la tradición manuscrita, pero es fácil llegar al mismo resultado por conjetura. Como sea, ni la divinatio ni una enmienda ope codicum tienen aquí peso suficiente para merecer una mínima anotación en la estimativa de Núñez.

Pero, en otros contextos, es improbable que el buen ojo editor sea por completo ajeno a los códices. Así, en 1499 el Comendador dedica una glosa de cierta extensión a los vv. 112egh, ciertamente estragados en la tradición impresa:

pues mucho devría ser más que culpado aquel coraçón que sin non querer quiere que quiera querido no ser princeps 14891496

pues mucho devría ser más que culpado aquel coraçón que, si non querer quiere, querría querido no ser, 1499

pues mucho devría ser más que culpado aquel coraçón que, si non querer quiere, que quiera querido no ser, 
En 1499 Núñez declara una corrección ope ingenii, y probablemente su enmienda tenga en verdad tal raíz:

Pues mucho devría ser más que culpado aquel coraçón que si non querer quiere que quiera. Por estar la letra d'esta copla depravada y mal escrita, ha estado hasta agora por entenderse. Yo, emendadas dos palabras, pienso que está restituida en su verdadera escritura y que se entenderá muy bien. Y es que por aquella parte $\sin$, quitada la $n$, se lea $s i$ conjunción condicional; y por aquellas dos partes que quiera se emiende querría [...]. En otra manera sería impossible entenderse. Y querrá entonces decir la letra esto: 'Mucho devría ser más que culpada la persona que, si no quiere querer bien a otra, no querría tampoco ser bien quisto d'ella' [...].

La modificación del segundo lugar crítico (querría por que quiera), sin atestiguar en la tradición del Laberinto, es desechada por Núñez en 1505, con la consiguiente simplificación de la glosa:

Peor y malvada condición es la de aquellos que no solo no aman a quien los ama, mas ante los aborrecen por ser d'ellos amados. A estos, como desagradecidos, reprehende el poeta en esta copla, la qual es muy clara y $<$ que $>$ no ha mester glosa, y hase de leer si non querer, non sin non querer, la qual depravación hazía la copla escura.

Si en la primera redacción del comentario se hacía hincapié en las extremas corrupción y dificultad de la estrofa, la reescritura de 1505 afirma su claridad, con el único cambio de si (non querer) con respecto a la princeps. La nueva propuesta, que atenúa el mérito de la enmienda, junto con la recuperación de la lectura documentada que quiera frente a la conjetura querría, induce a la sospecha de que Núñez ha localizado un códice con las lecciones defendidas, pues son bastantes los manuscritos en donde concurren ambas lecturas genuinas. Pero el Pinciano no lo declara.

Según se anticipaba al comienzo del apartado, estos silencios de la glosa a propósito de los códices serán ciertamente frecuentes, y abundantes correcciones del texto del Laberinto que coinciden con variantes atestiguadas carecen de cualquier anotación. Más común en el comentario de1505, la operación se sustancia ya en 1499:

1) se cobró la parte que estava perdida (21d)

cobra
PN7 NH5 BC3 LB2 SM1 HH1 MM1 1499

princeps 14891496 
2) de los pasados si quies ver espanto (61c) quieres

3) Los ojos dolientes al cerco baxando (130a) abaxando

4) padece tardanza, si quies que lo diga (181e) quieres

5) solo podremos ser redargüidos (183e) podemos

6) de Amiclas el pobre muy poco temía (227f) tenía
ML2 NH5 1499

princeps 14891496

PN7 et passim 1499

princeps 14891496

PN7 et passim 1499

princeps 14891496

PN7 et passim 1499

princeps 14891496

PN7 et passim 1499

princeps 14891496

Ninguna de estas correcciones merece la glosa de Núñez. Es cierto que, en algún caso, una lectura cuidadosa podría revelar erratas subsanables por conjetura, merced a la res metrica (ejemplos 2 y 4 ) o el sentido (6), sin necesidad de recurrir a la tradición manuscrita. Pero en otras ocasiones el matiz es tan delicado que solo el cotejo con otros testimonios patentiza la génesis de la enmienda. Y este proceso se incrementa de manera notable en la redacción de 1505: en el catálogo de enmiendas sin comentario de Núñez pulcramente establecido por Weiss y Cortijo, que reúne ciento veinticuatro lugares críticos, la mayor parte de las nuevas correcciones pone de manifiesto una tácita recognitio de los manuscritos ${ }^{30}$.

De hecho, las emendationes ope codicum del Comendador superan en número a sus conjeturas; cualitativamente, sin embargo, Núñez aprecia más la enmienda ope ingenii, que sus glosas realzan. La raíz de esta actitud editorial viene de antiguo. En las subscripciones de revisión latinas resulta excepcional el apunte de Estatilio Máximo (s. II d. C.), tanto por su cronología relativamente temprana como por la embrionaria recensio de seis testimonios ciceronianos que su declaración entraña ${ }^{31}$. Pero, según hemos advertido, en Roma la enmienda del texto es inhabitual y, cuando se produce, se funda más en la conjetura que en las variantes manuscritas. En el humanismo temprano, pese al sumo interés por el rastreo bibliotecario de manuscritos clásicos, la emendatio ope ingenii se considera la principal prueba de maestría filológica de mano de eruditos como Beroaldo. En contraste, Barbaro se muestra reticente hacia la conjetura, un mal a veces necesario, pero prescindible si hay alternativa documentada. Pero estas voces discrepantes en defensa de las lecciones atestiguadas, en particular de Poliziano y sus epígonos, fueron atendidas tardía

\footnotetext{
${ }^{30}$ Weiss y Cortijo, ed. cit., pp. 1029-1047.

${ }^{31}$ «Statilius Maximus rursum emendavi ad Tyronem et Laecanianum et Domitium et alios veteres tres». Vid. Reynolds y Wilson, ob. cit., pp. 59-61; y Tzetzel, Latin Textual..., pp. 206-231, y Critics..., pp. 87-88 y 203-210.
} 
y no unánimemente. En tal contexto, el comentario del Pinciano pertenece aún a la vieja escuela. No obstante, en su revisión de 1505, el mayor peso de las lecturas de los códices, aunque no alcance un rango cualitativo superior en la estimativa de Núñez, revela un incipiente cambio de actitud.

\title{
La guía de los «auctores» y las fuentes
}

En varios de los lugares críticos comentados se constataba cómo Núñez apuntala la argumentación mediante concordancias clásicas, generalmente en propuestas conjeturales -así 110c (zelos), 130b (Thirreo) o 259a (del aire se cría)-, pero también como refuerzo de alguna enmienda ope codicum-como en 166d (loó de más sano)-. En esta línea, el uso de las fuentes del Laberinto como referente para la fijación del texto es recurso relativamente común en el proceso editorial del Comendador.

La anotación del v. 37a ilustra bien el modelo:

\begin{abstract}
Vi de Euphratés al Mediterrano Vide a Éuphrates el PN7 et passim $1499^{\text {glosa }} 1505$ princeps $148914961499^{\text {texto }}$

Vide a Euphrates el Mediterrano. Assí se lee en todos los libros, pero corruptamente. Hase de emendar en esta manera para que concuerde con Anselmo, al qual, segund ya avemos dicho, sigue en toda esta cosmografía: «Vi de Euphratés al Mediterrano», y aquí vide no será una dición, sino dos, y querrá dezir que 'vio desde el río Éufrates hasta el mar Mediterráneo' las provincias siguientes [...]. Y assí se ha de entender este passo. No quiero ser arrogante y dezir que no se avía entendido este lugar hasta que yo le declaré y corregí, aunque cierto no diría en ello lo que no es (glosa de 1499).
\end{abstract}

Según la declaración de Núñez, la Imago mundi, atribuida por entonces a Anselmo, alienta la enmienda de «todos los libros», en referencia a la tradición impresa, que presenta lecturas erróneas. Sin embargo, PN7 y buena parte de los manuscritos aportaban ya las lecciones genuinas. Si bien resulta inverosímil que el Pinciano desconociese todos estos testimonios, la glosa de 1499 se cierra con una arrogante preterición, atenuada por la supresión de la concesiva postrera en 1505 («aunque cierto...»), que con todo mantiene lo esencial e incluso eleva al texto una enmienda que en 1499 había permanecido relegada al comento.

Según anticipaba el prólogo de 1499 (f. 3r), otra de las enmiendas que más satisface a Núñez, en torno a la alusión geográfica del v. 50a, tiene también su fundamento en las fuentes de Mena, ahora sin coincidencia con ninguna variante atestiguada en la tradición del Laberinto: 
El Catabathmón fue luego patente

Cáucaso monte

Caucabon monte
14991505

LB2 MM1

14891496

El Catabathmón fue luego patente. Así se ha de leer, no Caucabon monte como hasta agora corruptamente se ha leído. Y es Catabathmón, como escrive Plinio en el libro quinto de la Historia natural, un lugar y un valle de África, fin de la provincia Cirenaica. Confirman más esta mi corrección las palabras de Anselmo, a quien sigue Juan de Mena en toda esta cosmographía, como ya otras muchas vezes he dicho, las quales son estas: «Hec a Parethonia civitate et a montibus Catabathmon sumit initium et in aris Philenorum finit»; quiere dezir: 'Esta provincia Libia comiença desde la cibdad Parethonia y desde los montes de Catabathmón y hace fin en las aras de los philenos». Los que en Plinio emiendan Catabathyno por Catabathmon, como es Marco Antonio Sabellico y otros, yerran gravemente, porque todos los auctores, así griegos como como latinos, pronuncian Catabathmo: Plinio, Strabón, Ptolomeo, Pomponio Mella, Didodoro, Eustachio, Stéphano, Dionisio, Marciano, Solino, Antonino. En Paulo Orosio corruptamente se lee Catabathyno por Catabathmo, y la misma depravación está en Salustio (glosa de 1499).

El lugar crítico es confuso, de donde las variantes deturpadas de los manuscritos y el espacio en blanco de la princeps (vid. supra), todo ello anticipado por las propias variantes de la tradición grecolatina. Como ha señalado Alonso, la censura de Sabellico y las concordancias clásicas de la glosa de Núñez calcan una de las Castigationes Plinianae de Barbaro ${ }^{32}$. En 1505 se abrevia la nota mediante la corriente omisión de la cita latina, solo traducida, y la supresión de la referencia a Sabellico, aunque se mantiene el espíritu de la glosa original. Entre los editores modernos del Laberinto, si bien Kerkhof prefiere mantener la lección manuscrita Cáucaso monte, que entiende como error geográfico imputable a Mena, domina la aceptación de la enmienda que Núñez ha basado en las fuentes.

Fuera del mapamundi del Laberinto, otra de las autoridades en que a menudo se apoya el Comendador para sostener enmiendas análogas es Lucano:
1) Jonos primero halló la moneda (229a) Jonas
14991505
Yonus
princeps 14891496
LB2 et passim

Jonos primero falló la moneda. [...]. Por lo qual parece que se podría conveniblemente leer en esta copla no Jonas, como en todos los libros está depravado, sino Janus. Pero a mi parecer ni se ha de leer Jonas ni Janus, sino Jonos, el qual fue rey de Thessalia en Grecia y inventó primero la moneda, segund

${ }^{32}$ Vid. Alonso, art. cit., pp. 12-13. 
que Lucano escrive en el sexto de la Farsalia en estos versos, los quales imita Juan de Mena: «Primus Thessalice rector telluris Jonos in forman calide [...]» (glosa de 1499, con variantes ortógraficas en 1505).

2) díxole: Hécate, non te hagan guerra (250c) 14991505 díxole cata Échate dixo princeps 14891496 NH5 et alii

Díxole cata. Esta palabra «díxole cata» no tiene a quién se pueda referir; por ende pienso que por cata se ha de leer Hécate, d'esta manera: «Díxole: Hécate, no te hagan guerra». Y digamos que habla con la diosa Proserpina, reina del Infierno, que por otro nombre la llaman los poetas Hécate. Y que se aya de leer así confírmalo Lucano, del qual nunca se aparta en todo esto Juan de Mena, cuyas palabras son, segund que luego diré, estas: «Ficta sole Hecate pallenti tabida forma» (glosa de 1499, con leves variantes en 1505).

3) tábida, aborrida y sin alabança (250h) $\quad$ PN7 et alii 14991505 tu vida

BM1 et al. princeps 14891496

Tu vida. Se ha de emendar tábida, porque lo más que aquí ser pudiere avemos de concertar al poeta con Lucano, el qual dize: «Pallenti tabida forma». Tábida quiere dezir 'cosa emponçoñada y amarilla'; y sin esto no ternía la copla ningún intellecto si se leyesse tu vida [...] (glosa de 1499, con variantes ortográficas en 1505).

En el primer ejemplo -en donde precede a nuestra cita una relación de concordancias clásicas que apuntan a la forma Janus-, la enmienda Jonos, que Núñez propone desde la Farsalia, carece de documentación en el corpus del Laberinto. En cambio, la variante tábida de la última muestra figura en varios códices, en tanto que la lectura aventurada para el segundo lugar crítico se documenta parcialmente. Si el Pinciano se ha inspirado aquí en lecciones manuscritas, lo calla, pues tales silencios confieren mayor relieve a su rastreo de las fuentes y su proyección sobre el texto de $\mathrm{Mena}^{33}$.

El recurso a los auctores en el comentario humanístico tuvo un firme defensor en Poliziano, cuya Miscellanea pondera el valor de las fuentes griegas en los estudios latinos, y propugna un análisis comparativo. Aunque a Poliziano le interesan especialmente las posibilidades exegéticas del método, también lo considera en la fijación del texto, en especial en lo atinente a términos helenos en obras latinas y a los pasajes traducidos o imitados del griego. El principio fue adoptado por Barbaro, Aldo Manuzio o Erasmo, entre

\footnotetext{
${ }^{33}$ Otras enmiendas basadas en las fuentes se apuntan en las glosas a $38 \mathrm{~g}$ (Eutropio), 45c (Imago mundi), 48g (Isidoro e Imago mundi), 128ef (Eusebio), 150d (Ovidio) y 228f (Justino, Cicerón, Valerio Máximo, Estrabón, Solino, Plinio «y otros auctores»).
} 
otros. En contraste, Beroaldo hizo un uso limitado de los auctores griegos, y generalmente ceñido a obras ya vertidas al latín ${ }^{34}$.

Algunas anotaciones de Núñez concuerdan con el planteamiento de Poliziano incluso en el dominio exegético. Por ejemplo, a raíz de la copla 151 del Laberinto, el Comendador intenta explicar la momificación de cadáveres bajo las arenas del desierto mediante Heródoto, Trogo y Gelio. La remisión a los clásicos resulta forzada, pues ninguno de los auctores invocados trata de la momificación espontánea, sino de muertos sepultados por tormentas de arena. A Núñez le falta la clave de las Andanzas de Pero Tafur, coetáneo de Mena y también «veinticuatro» de Córdoba, con toda probabilidad fuente del Laberinto aquí ${ }^{35}$. Pero la ilustración del Pinciano tiene mérito erudito, que en este caso busca iluminar el texto sin la pretensión de enmendarlo.

Más común será, empero, que Núñez recurra a las fuentes del Laberinto para establecer su texto. En este sentido, la contención de Poliziano a la hora de manejar las concordancias grecolatinas como referente crítico-textual no fue unánime en su tiempo. Así, Valla (Adnotationes in Novum Testamentum, 1449) había propuesto la enmienda de la Vulgata latina a partir de manuscritos griegos; y, con este pie, Erasmo, en la primera edición de su Nuevo Testamento griego (1516), incluso se permite rellenar lagunas del Apocalipsis con los pasajes correspondientes de la Vulgata traducidos al griego ad hoc.

En este contexto ecdótico, sin alcanzar tales extremos, no es extraño que Núñez adoptase las fuentes de Mena como guía para pulir el texto del Laberinto. Por lo demás, su tino al determinar la Imago mundi, la Farsalia o la Eneida como modelos directos sanciona en buena medida el instrumento. Como apoyo de una enmienda ope codicum -según se hace de modo explícito a propósito de la lectura «loó de más sano» (166d), autorizada por Virgilio-, es probable que Núñez recurriese a la fuente para orientar su selección de variantes más a menudo de lo que declaran sus glosas. Pero dado que, según todas las evidencias, el Pinciano tiende a ocultar la consulta de manuscritos para mayor lustre de su ingenium, por lo general su recurso a las fuentes actúa expresamente al servicio de la conjetura.

${ }^{34}$ Vid. Grafton, ob. cit., pp. 32-44, y Defenders of the Text. The Traditions of Scholarsip in an Age of Science (1450-1800), Cambridge (Massachusetts)-London, Harvard University Press, 1991, pp. 64-72; y Ciapponi, ed. cit., pp. 9-10.

${ }^{35} \mathrm{Vid}$. J. Casas Rigall, «Texto y glosa: "e como en arena do momia se espera” (Mena, Laberinto, 151e)», en En memoria de tanto miragre. Estudos dedicados ó profesor David Mackenzie, ed. de F. Dubert et al., Santiago de Compostela, Universidade, 2015, pp. 75-89. 


\section{La difusión del método de Poliziano}

En 1577 José Justo Escalígero publica una edición de Catulo según el método de recensio de Poliziano, en donde, además del examen y filiación de los testigos, afronta incluso la reconstrucción del arquetipo, yendo así más allá que el filólogo italiano ${ }^{36}$. Grafton ha analizado en detalle el itinerario ecdótico de Escalígero: tras sus primeras ediciones, caracterizadas por la confianza en la conjetura y un examen asistemático de la tradición textual, un desliz académico lo induce a abrazar la objetiva materialidad de los códices y las lecciones documentadas a la manera de Poliziano, aunque la mala acogida de su Catulo en Italia lo devolverá a la cultura del ingenium. Al margen de los pasos biográficos en este camino de ida y vuelta, es indudable que Escalígero estudió a fondo el método de Poliziano y su escuela, beneficiado por la perspectiva histórica, de manera que su palinodia final implica un profundo conocimiento de causa.

No es este el caso de Núñez a la altura de 1496-1499, porque, a finales del s. Xv y aún en las primeras décadas del s. XVI, Poliziano fue leído y apreciado antes como creador, mientras sus más finas propuestas ecdóticas eran poco conocidas, y no cabalmente. Es lógico, porque, a causa de su prematura muerte, Poliziano no pudo dar a la imprenta ninguna edición de relieve, y su principal legado ecdótico permaneció manuscrito en un ingente volumen de marginalia autógrafos en los manuscritos que estudió. De sus obras publicadas en vida, la primera centuria de Miscellanea da idea de su método editorial; pero, justamente por su carácter técnico, no fue uno de sus escritos más difundidos en Europa: entre 1480 y 1559, la Miscellanea está entre sus obras menos impresas (7 ediciones), frente a las Sylvae (31), Lamia (29) y las Epistulae (26). Incluso a un lector avezado como Beroaldo apenas se le alcanzan las ideas fundamentales de la Miscellanea, ni siquiera la importancia de la identificación precisa de las fuentes manuscritas o la enmienda ope codicum, menos aún el método genealógico. En general, según ha estudiado Coroleu desde la perspectiva hispánica, hasta mediados del s. XvI Poliziano y los humanistas italianos de su época son particularmente reconocidos por sus imitationes neolatinas ${ }^{37}$. Por más que Poliziano tuviese discípulos directos como Pietro Crinito (c. 1465-c. 1507) o Pietro Bembo (1470-1547), la reivindicación y desarrollo de su metodología ecdótica es empeño de Piero Vettòri

${ }^{36}$ Vid. Timpanaro, ob. cit., pp. 9-11; y Grafton, Joseph Scaliger ..., pp. 161-179.

${ }^{37}$ Vid. A. Coroleu, Printing and Reading Italian Latin Humanism in Renaissance Europe (ca. 1470ca. 1540), Newcastle, Cambridge Scholars, 2014, de donde tomo los datos de las ediciones de Poliziano (pp. 125-126). 
(1499-1585) y sus colaboradores, entre quienes se encontraba el español Antonio Agustín (1517-1586). Y lo mismo cabe decir al respecto de la discusión de los límites del método: si bien Poliziano tuvo un acérrimo detractor coetáneo en Giorgio Merula (c. 1430-1494), el debate se agitaría más tarde, a raíz de los desarrollos de Vettòri y sus adversarios de escuela francesa ${ }^{38}$.

En el comentario de 1499, con pie en la alusión a Mesopotamia (Laberinto, v. 36b), Núñez insiere una elogiosa mención de Poliziano:

Y Mesopotamia cómo se tendía [...]. Llaman algunos escriptores a esta provincia inter amnana siguiendo la etimología del nombre griego, porque está, como antes dixe, inter duos amnes, quiere dezir, 'entre dos ríos'. Assí la llama Lampridio en la Vida del emperador Aurelio Alexandre, y Ángelo Policiano florentino, en cuya muerte poco ha hizieron las sciencias de humanidad grande y incomparable jactura, en el tercero libro de la interpretación del historiador Herodiano.

El panegírico de Poliziano por los humanistas de su tiempo es común, pero no se funda tanto en su método editorial cuanto en la erudición clásica de las cuatro Sylvae (Manto, Rusticus, Ambra y Nutricia). Así, según recuerda Rico, en su Tertia quincuagena (1517) Nebrija se refiere a Poliziano como «nostro seculo vir omnium eruditissimus» ${ }^{39}$. Sin embargo, aunque teoría y práctica conduzcan al gramático hispalense a postulados ecdóticos certeros -así, en la Apologia a Cisneros (c. 1507) defiende la buena lectura aislada frente a una torpe variante atestiguada mayoritariamente y, aun sin emplear ningún marbete sintético, propone la eliminatio codicum descriptorum ${ }^{40}$, sus ediciones no se basan en una recensio al modo de Poliziano, sino en la vulgata de turno; y, por ejemplo, para el texto de la Psycomachia de Prudencio (c. 1502 y 1512) toma como base la edición aldina de 1501, que parece cotejar con la princeps de hacia 1492 y acaso algún manuscrito, conjunto al que incorpora sus conjeturas ${ }^{41}$. Algo semejante cabe decir de Erasmo, quien, declarado admirador de Poliziano, pese a concebir la idea de arquetipo más claramente que Vettòri, manifiesta notable inclinación hacia la conjetura y

${ }^{38}$ Vid. Grafton, Joseph Scaliger..., pp. 45-100. Merula dejó inédita su diatriba In Politianum por consejo de Bartolomeo Calco y su propia muerte inesperada (vid. Branca y Pastore Stocchi, ed. cit., p. 4).

${ }^{39} \mathrm{Vid}$. F. Rico, Nebrija frente a los bárbaros, Salamanca, Universidad, 1978, pp. 53-67 [66].

${ }^{40} \mathrm{Vid}$. Antonio de Nebrija, Apologia, ed. de B. Macías, estudio de P. Martín Baños, Huelva, Universidad, 2014, cap. XIV, pp. 136-137. De acuerdo con Martín Baños (ibidem, pp. 24-25 y 77-81), es probable que Nebrija haya tomado ambos principios del prólogo de Erasmo a su edición de las Adnotationes in Novum Testamentum de Valla (1505).

${ }^{41}$ Vid. Aurelii Prudentii Clementis V. C. libelli cum commento Antonii Nebrissensis, ed. de F. González Vega, Salamanca, Ediciones Universidad, 2002, pp. 91-111. 
obvia la recensio sistemática, como muestran sus ediciones de Séneca, muy descuidada la primera (1515) por la premura y pésima corrección de su estampa, y no mucho mejor la segunda (1529), cuyo texto iba siendo modificado aquí y allá en pleno proceso de impresión a medida que Erasmo conocía nuevos manuscritos.

La biblioteca, los escolios autógrafos de sus libros y el epistolario de Núñez revelan sus principales lecturas de Poliziano ${ }^{42}$. La citada versión latina de Herodiano, en estampa aldina de 1503, estaba en su colección (Salamanca, imp. 34.133). Otras ediciones son ya posteriores a 1505. Así, el Juvenal comentado por Johannes Britannicus con adnotationes de Poliziano (Milán: Minutianus, 1514; Salamanca, imp. 34.185) y sus Epistulae (París: Gaudoul, 1515; Salamanca, imp. 32.774/3). No se conserva el ejemplar de las Sylvae que el Comendador seguramente poseyó, a tenor de las listas bibliográficas en las guardas de otros de sus libros (HG II. 1 y XVIII). En la epístola que Núñez dirige a Juan de Vergara el 20 de marzo de 1522, habla de su comentario de tres silvas (Manto, Ambra y Nutricia), que al parecer nunca se llegó a imprimir (carta 2, post data). Otras referencias epistolares a Nutricia se encuentran en las cartas 10 (23-I-1539), 12 (21-IV-1539) y 19 (13-IX-1541), todas para Jerónimo Zurita. Análogamente, en sus glosas marginales hay abundantes referencias a este mismo poema, y en menor medida a Ambra y Manto. En fin, sin referirse a títulos concretos, en la epístola a Villalobos de 1525, a raíz del comentario de los dos primeros libros de la Historia natural de Plinio publicado por este último, un implacable Núñez presenta una nómina de eruditos que a su juicio serían óptimos glosadores de una obra tan compleja, que lógicamente incluye a Barbaro y también a Poliziano (carta 5). Ante este panorama, es natural que, al lado de auctores como Plinio, Núñez emplease las Sylvae como texto universitario en las aulas de Alcalá y Salamanca ${ }^{43}$.

Aunque la Miscellanea no haya aparecido en el catálogo precedente, se han aducido indicios de que Núñez conocía la obra, una lectura por otra parte esperable entre los más pulidos humanistas del período.

De este modo, en el comentario de 1499, sobre la «ciega Fortuna» (Laberinto, v. 267b), Núñez apunta concordancias de Séneca y Ovidio, y censura el error certe por coece en editores como Accursio Pisano. Y a raíz de esto último, añade: «Pero d'estas emendaciones en los auctores latinos más oportunamente trataremos en un libro de annotaciones que por horas succesivas elucubramos en lengua latina, el qual en breve con el favor divinal saldrá a luz». Weiss y Cortijo advierten aquí el pulso inspirador de la Miscellanea,

${ }^{42}$ Las signaturas y referencias que siguen proceden de Signes et al., ob. cit.

${ }^{43}$ Vid. Coroleu, ob. cit., pp. 107-109. 
que ilustra el subgénero filológico en cuestión ${ }^{44}$. Sin embargo, al margen de las Noches áticas de Gelio, modelo clásico de esta progenie de análisis, otros humanistas italianos habían precedido a Poliziano. Es el caso de Calderini, quien anunció la composición de tres libros de Observationes de este tenor, de los que solo conservemos un extracto impreso en $1475^{45}$. Más sintomático resulta que, meses antes de la estampa de la Miscellanea, Beroaldo hubiese publicado sus Annotationes centum (1488), dedicadas en parte a la exégesis, en parte a la crítica textual de diversos clásicos latinos. De hecho, la nota autógrafa de Núñez en referencia a Beroaldo como «praeceptor noster» remite en particular a esta obra, según ha puntualizado Signes ${ }^{46}$. Los nombres de Calderini y Beroaldo fueron silenciados por Poliziano, que presenta su Miscellanea como obra de nuevo género, con una maliciosa alusión epilogal a un conocido suyo, autor de un centenar de anotaciones recién publicadas, que supuestamente le robó la idea. Pero Beroaldo ya había dedicado unas Annotationes a Plinio en 1476, de carácter textual, y a Servio en 1482, de tipo exegético, en donde anunciaba explícitamente las glosas misceláneas que verían la luz en $1488^{47}$. En consecuencia, el apunte de Núñez debe de referirse a este nuevo modelo de comentario humanístico, y no a la Miscellanea en especial. Incluso, a decir de Alonso, al declarar una elaboración intermitente (por horas succesivas 'a ratos perdidos'), el cierto desdén de Núñez hacia el subgénero, por más que tópico, lo acerca a Calderini y Beroaldo más que a Poliziano, este muy pagado del nuevo modelo. La referencia fue eliminada en 1505 , lo cual apunta a que el Comendador desechó el proyecto, que no ha dejado rastro manuscrito ni impreso.

Otra evaluable huella de la Miscellanea en la obra de Núñez ha sido propuesta por Coroleu ${ }^{48}$, que considera el comentario parcial y anónimo de $\mathrm{Nu}$ tricia en el ms. 3663 de la Biblioteca Nacional como posible obra del Pinciano, esto es, una sección de aquel comento de las Sylvae a que Núñez se refería en su correspondencia. En un caso, un pasaje con voces hebreas del poeta es suplementado en el comentario manuscrito con un fragmento de la Miscellanea. Aunque, en conjunto, estas glosas anónimas sean básicamente una paráfrasis -en particular de términos oscuros o alusiones mitológicas e históricas-, con escasa atención al elemento gramatical, poético y textual, no cabe descartar que sean obra de Núñez, ya directa, ya la refundición de otro

\footnotetext{
${ }^{44}$ Vid. Weiss y Cortijo, ed. cit., p. 1153.

${ }^{45}$ Vid. Gaisser, art. cit., pp. 279-284.

${ }^{46} \mathrm{Vid}$. Signes et al., ob. cit., p. 10.

${ }^{47}$ Vid. Ciapponi, ed. cit., pp. 17-18.

${ }^{48}$ Coroleu, ob. cit., pp. 107-109.
} 
comentarista, tal vez uno de sus alumnos. En cualquier caso, la cronología del comentario de las Sylvae por Núñez -así, la carta a Vergara- apuntaba a una fecha muy posterior a 1505 .

Pese a la inseguridad de estos rastros, lo esperable es que Núñez, formado en la Italia coetánea de Poliziano, conociese su método in situ y la Miscellanea desde fecha temprana, pues el prestigio erudito del autor auspiciaría la difusión de su obra cuando menos en los círculos filológicos más especializados. Porque, si bien el influjo de Poliziano no se deja notar de modo patente en el comentario y el texto del Laberinto, sí se aprecia una diferencia de grado entre las ediciones de 1499 y 1505 , según se argumenta en el apartado final.

\section{Corolario}

La potencial influencia de Poliziano en el concepto editor y anotador de Núñez no debe inducirnos a preterir a otros clásicos y humanistas de igual o mayor peso en el comentario del Laberinto, por añadidura bien representados en la biblioteca, los escolios y el corpus epistolar del Comendador.

Por ceñirnos a los nombres más citados en nuestras páginas, el Virgilio de Servio estaba obviamente en su colección (Venecia: De Soardis, 1491; Complutense, FLL I/49), al igual que Gelio (Venecia: Andreas Jacobus, 1477; Salamanca, inc. 130). Servio, además, es citado a menudo en los marginalia de Núñez -así, en el ms. 295 y los incunables 221, 299, 313 y 366, todos en la biblioteca universitaria de Salamanca-. El anterior volumen veneciano de Virgilio contenía también las glosas de Calderini, asimismo representado en la biblioteca del Pinciano por las anotaciones a Estacio, Propercio y la $\mathrm{He}$ roida 15 de Ovidio (Venecia: De Paganinis, 1490; Salamanca, inc. 221), y de nuevo la Heroida 15 y el Ibis ovidianos (Venecia: Tacuinus, 1501; Salamanca, imp. 39.532/2), así como por alusiones en escolios autógrafos -en estampas de las Heroidas (Parma: Portilia, 1481; Salamanca, inc. 268/1) y Ausonio (Venecia: Tacuinus, 1507; Salamanca, inc. 299/1)-. Con respecto a Beroaldo, además de la referida remisión a sus Annotationes centum (Salamanca, inc. 147), está presente en la biblioteca de Núñez mediante la edición comentada de las Catilinarias de Cicerón (Venecia: De Zannis, 1513; Salamanca, imp. 35.098) y un Ovidio glosado, este entre los libros del Comendador actualmente perdidos (n. ${ }^{\circ}$ 133). En fin, Barbaro se localiza en la biblioteca gracias a las Castigationes Plinianae (Roma: Silver, 1492; Salamanca, inc. 313), una antología de Aristóteles (Venecia: Pincius, 1505; Salamanca, imp. 13.815) y sendas ediciones comentadas de Dioscórides (n. $\left.{ }^{\circ} 78\right)$ y Temistio (n. $\left.{ }^{\circ} 156\right)$, ejemplares hoy perdidos; además, en las epístolas se cuentan referencias a su 
edición de Mela (cartas 24 [22-II-1543] y 25 [11-VI-1543], ambas dirigidas a Zurita), así como el antedicho elogio de su erudición ejemplar en la carta a Villalobos ${ }^{49}$.

Alonso ha estudiado en detalle la huella de los humanistas italianos en la glosa de Núñez, en forma de alusiones expresas o tácitas ${ }^{50}$. En la introducción de 1499, el accessus al Laberinto se cierra con un catálogo de auctoritates en donde los nombres más recientes pertenecen a la generación anterior -Lorenzo Valla ( $\uparrow 1457)$, Biondo $(\dagger 1463)$, Tortelli ( $\uparrow 1466)$ o Filelfo $(\dagger 1481)-$, aunque después no todos sean efectivamente aprovechados en la glosa ${ }^{51}$. No se incluye en la relación a Bruni ( $† 1444)$, que sí es invocado en el curso del comentario, y lo mismo ocurre con el joven pero recién fallecido Poliziano (†1494). En cambio, se toman sin mención pasajes del coetáneo Barbaro $(\dagger 1493)$ contra Sabellico (vid. supra), y muy probablemente de un autor vivo, Lucio Marineo Sículo (glosa 47ef). Weiss y Cortijo entienden que las citas obviadas obedecen a un modelo de comentario en donde, a la manera de Plinio, el comentarista ha asimilado sus fuentes hasta hacerlas suyas. Es lo usual por el tiempo, y los mismos Barbaro y Poliziano a menudo aprovechan a sus contemporáneos sin nombrarlos, según se ha visto. Con todo, en consonancia con Alonso, es obvio que estos silencios potencian el propio lucimiento de Núñez. En esta línea, citas expresas de Bruni y Traversari (119a), o más habitualmente Tortelli $(6 \mathrm{~b}, 53 \mathrm{~b}, 121 \mathrm{f}$ y $143 \mathrm{gh})$, tienen por objeto censurar y corregir sus afirmaciones para mérito personal. Tales dicterios desaparecen en 1505, proceder en donde Alonso aprecia a un filólogo más seguro de sí, que no siente la necesidad del palmetazo para brillar. En todo este conjunto, en fin, extraña la aparente ausencia de Beroaldo, máxime cuando, en contraste, Núñez dedica encendidos elogios a otro de sus maestros, Antonio de Nebrija -glosas 143gh y 284f, la segunda alusión omitida en 1505 (vid. infra)-; si acaso, en la referencia al subgénero de la miscelánea se halla subsumida una alusión al autor de las Annotationes centum.

En el tránsito de la Glosa de 1499 a 1505 perduran constantes en el concepto de Núñez, pero también novedades que afectan sobre todo al elemento crítico-textual.

\footnotetext{
${ }^{49}$ Todos los datos y referencias proceden de Signes et al., ob. cit.

${ }^{50}$ Para contextualización, vid. asimismo el panorama general de los auctores en el Laberinto de Núñez, antiguos y modernos, en Weiss y Cortijo, ed. cit., pp. 101-104.

${ }^{51}$ La supresión del accessus de 1499 en 1505 llevaría aparejada la eliminación de este catálogo; vid. J. Casas Rigall, «El accessus a Juan de Mena en tres comentaristas del Laberinto de Fortuna (anónimo del Cancionero de Barrantes, Hernán Núñez y el Brocense)», en Bulletin Hispanique, 118 (2016), pp. 431-452.
} 
El uso de una versión vulgata como texto base, característico del humanismo incluso después de la renovación de Poliziano y su escuela, es común a ambas ediciones del Laberinto. Se mantiene asimismo el moroso comentario verso a verso, derivado de Servio y habitual entre los humanistas hasta 1480. En la obra de Beroaldo se advertía el cambio de tendencia entre su comentario de Propercio, de vocación enciclopédica, y las Annotationes selectas de Plinio y Servio, un modelo que reivindicarán de manera más decidida Poliziano o Barbaro. Núñez, que declara en la glosa de 1499 su interés por el género de la miscelánea filológica, solo optará por el nuevo método de anotación selectiva en posteriores trabajos sobre autores clásicos. De resultar fidedigna la anécdota referida por Bernardino Daza, según la cual el Comendador abominaría de su glosa del Laberinto, uno de los condicionantes, además de su preferencia por el canon grecolatino, debió de ser la prolija exhaustividad del comento meniano, ya demodé a finales del s. Xv, que el Pinciano pronto asumiría para abrazar la glosa selecta ${ }^{52}$.

La constricción de las anotaciones a lugares especialmente difíciles de la obra favorecería una mayor proporción de comentos sobre crítica textual. Por esta causa, el volumen de notas textuales de Núñez al Laberinto, con no ser despreciable, queda oscurecido por una exégesis más interesada en los realia, las concordancias clásicas y el alarde erudito. Por lo que respecta a la formalización de las enmiendas propuestas, en 1499 con frecuencia permanecen en la glosa, al modo de los comentaristas antiguos. Es verdad que la escuela de Poliziano y Barbaro sancionan esta alternativa; pero en 1505 el Comendador va por otro camino y, sin coherencia absoluta, tiende a consignar sus lecturas en el cuerpo del texto. Antes que refutación consciente, la estrategia de Núñez apunta a solución práctica a que el proceso de lima del texto conduce de manera natural, y de hecho será adoptada por Lachmann. En relación con esto, en los casos en que se confía al juicio del lector la elección entre variantes delicadas, Núñez está empleando una estrategia didáctica característica de Beroaldo, si bien el mismo Barbaro deja a veces en suspenso una decisión textual insegura ${ }^{53}$.

Ya en 1499 aprovechaba el Pinciano las fuentes y las concordancias clásicas como referente textual, según la desiderata de Poliziano y Barbaro. Pero, en el dominio de la emendatio, la conjetura es el elemento de que Núñez hace

${ }^{52}$ Vid. Bernardino Daza, Los emblemas de Alciato traducidos en rimas españolas, Lyon, Rouillé, 1549, p. 12; ed. facsimilar, pról. de R. Zafra, Barcelona, Olañeta-Universitat de les Illes Balears, 2003. Así lo señalan Weiss y Cortijo, ed. cit., p. 53.

${ }^{53}$ De esta manera, en el libro VI de la Naturalis historia, Barbaro evita una decisión en 34 casos de un total de 372 lugares críticos analizados (vid. Pozzi, ed. cit., p. lxxvii). 
más ostentación, en la línea de Beroaldo y la mayor parte de sus contemporáneos. Barbaro y sobre todo Poliziano son ahora la excepción en la defensa de las lecciones atestiguadas en los viejos códices. El Pinciano, si bien no identifica sus testimonios ni mínimamente -en esto, el propio Barbaro fue asimismo impreciso-, recurre ya con relativa frecuencia a la tradición manuscrita del Laberinto en 1499. Cosa distinta es que sus anotaciones lo registren, pues incluso se presentan como conjeturas lecciones probablemente traídas de los códices. Este proceso se incrementa en la edición de 1505, cuyo texto incluye numerosas correcciones sin glosa que se documentan en manuscritos de Mena. Ello indica que, en realidad, los métodos de Poliziano y Barbaro no han caído por completo en saco roto, y que el Comendador ha afinado su edición mediante un aprovechamiento mayor de los códices. En las Castigationes a Séneca (1536) y las Observationes plinianas (1544), Núñez hará un uso mayor de los testigos manuscritos, también mejor identificados ${ }^{54}$. Pero a la altura de 1499 e incluso en 1505 la asunción del nuevo modelo era ciertamente limitada. Aunque en su obra de madurez Núñez siga confiando en la tradición indirecta -en sus Castigationes a Mela (1543) no parece haber consultado códices de primera mano- y en la conjetura mal atestiguada -según le recrimina amistosa pero severamente Juan Ginés de Sepúlveda a propósito del Plinio ${ }^{55}$-, constan pruebas tempranas del valor que otorgaba a las lecciones manuscritas frente a la versión vulgata y el ingenium: en una de sus estancias formativas en Italia -seguramente la segunda, entre ambas estampas del comentario del Laberinto-, el Pinciano entresacó del codice B de los bucólicos griegos las principales lecturas discrepantes en el texto de Teócrito con relación a la estampa aldina de 1495, variantes que consignó en el ms. 295 de la Universidad de Salamanca ${ }^{56}$. De manera análoga, de 1499 a 1505 , el texto del Laberinto y algunas glosas revelan tenuemente un cambio en la estimación de la tradición manuscrita.

Respecto de la primera edición, en 1505 hay una omisión muy llamativa, no fácil de explicar: en el citado envío al Herodiano latino de Poliziano (v. $36 \mathrm{~b}$ ), se suprime la nota laudatoria «en cuya muerte poco ha hizieron las sciencias de humanidad grande y incomparable jactura». Para justificación,

${ }^{54} \mathrm{~A}$ este respecto aún resulta útil el panorama pionero de M. ${ }^{\mathrm{a}}$ Dolores de Asís, Hernán Núñez en la historia de los estudios clásicos, Madrid, s. e., 1977, pp. 143-203.

${ }^{55}$ «Illud igitur pro iure nostrae amicitiae te hortor et moneo, ut in alienis scriptis castigandis temperantius agas, nec auctoris verba sine certissima ratione praeter omnium exemplarium fidem invertere, aut quoquo modo mutare animum inducas, hoc enim periculosum habetur» (carta 71, ed. de A. Domingo, en Signes et al., ob. cit., p. 374).

${ }^{56} \mathrm{Vid}$. A. Tovar, «Fernán Núñez de Guzmán sobre el códice B de los Bucólicos griegos», en Emerita, 13 (1945), pp. 41-48. 
Weiss y Cortijo recurren a la fecha de fallecimiento del humanista italiano, el año 1494: en 1499 el deceso había ocurrido poco ha, pero en 1505 mediaba ya más de una década ${ }^{57}$. La hipótesis no deja de resultar convincente; con todo, de ser esta la única causa, la simple supresión de la locución temporal trisílaba sería suficiente para adecuar la nota. ¿No habrá aquí algo más? Como alternativas, si pensamos en la materialidad bibliográfica del impreso de 1505 , no persuade una supuesta compresión del texto provocada por la mala «cuenta del original», pues el pasaje omitido, muy breve, está al principio del cuadernillo c (f. 17r), contexto impropio para esta clase de reajustes ${ }^{58}$. En cambio, tal vez aporte una clave la nueva actitud del Núñez de 1505, más comedido al corregir errores ajenos. En el extremo opuesto, humanistas como Valla y el propio Poliziano se caracterizaron por el afán polémico y la censura cruel, estrategia comprensible cuando el descrédito del competidor podía favorecer mecenazgos y cátedras. No fue este el caso del patricio Beroaldo, quien antes bien rehuyó el debate agrio y continuó mostrando su respeto por Barbaro y Poliziano pese a los malévolos desaires que recibió de ambos. Beroaldo falleció el 17 de julio de 1505, y la segunda redacción del comentario del Comendador se acabó de imprimir a 7 de noviembre del mismo año. Acaso el tono más moderado de Núñez e incluso la eliminación del elogio del desabrido Poliziano deriven en parte de las enseñanzas de Beroaldo en homenaje al preceptor.

Al tiempo, no cabe descartar que esta omisión de la loa a Poliziano tenga una raíz teórica. Según se ha constatado, aunque la glosa de Núñez no lo remarque, en 1505 hay un recurso mayor a la tradición manuscrita. Dada la inexistente identificación de sus testigos, no sabemos si el Pinciano simplemente ha aprovechado mejor los materiales que ya conocía hacia 1499 o si se ha procurado nuevos testimonios. Esto último sería más claro síntoma de que los métodos propugnados por Barbaro y Poliziano inciden en sus planteamientos. En cualquier caso, al tamizar mejor el texto base de la vulgata a través de los códices, el Comendador se acerca más, por poco que sea, al nuevo modelo. Pero si Núñez fue capaz de verlo, también advertiría que su Laberinto estaba lejos de adecuarse a los presupuestos de las Castigationes

${ }^{57}$ Vid. Weiss y Cortijo, ed. cit., p. 107.

${ }^{58}$ En contraste, posiblemente obedezca a esta causa la supresión del elogio de Nebrija en la glosa $284 f$ (f. 132r, sign. $\mathrm{r}^{4}$ ), pues en toda esa sección, dentro del cuadernillo final del impreso, hay numerosos recortes que propician la ubicación del colofón y la marca tipográfica de Juan Varela en el anverso del f. 136 y último, contexto visualmente más destacado y materialmente mejor protegido que el reverso, este en blanco. Cfr. Weiss y Cortijo, ed. cit., p. 36, que en principio apuntan a la atenuación de elementos autobiográficos por Núñez para motivar esta omisión, si bien en una nota posterior reconocen cómo «no deja de ser curioso que se pierda el elogio original a su maestro» (ibidem, p. 951 n.). 
Plinianae y la Miscellanea, porque en 1505 también aumenta el número de conjeturas consignadas en el texto del poema sin señal. Por ello, convenía una declaración programática, siquiera tácita. De Barbaro se había valido sin cita ya en 1499; en parte, en 1505 le llega el turno a Poliziano, ahora solamente mencionado como mero traductor de un autor de segunda fila. La paradoja es notable, según esto, porque el elogio de Poliziano desparece cuando Núñez comienza a entrever el alcance de su método.

Recibido: 20/01/2020

Aceptado: $1 / 05 / 2020$ 


\title{
$\cos$
}

HERNÁN NÚÑEZ ANTE EL TEXTO DEL LABERINTO: ELEMENTOS DE ECDÓTICA ANTIGUA Y HUMANÍSTICA

Resumen: La edición y comentario del Laberinto de Mena por Hernán Núñez, con dos versiones (1499 y 1505), ilustra la encrucijada del filólogo humanista, entre el escoliasta tardoantiguo y la moderna evolución del modelo. El uso de la vulgata impresa como texto base, la proporción de anotaciones de crítica textual y la presentación formal de las variantes, la preponderancia de la enmienda ope ingenii sobre la enmienda ope codicum y el uso de las fuentes como guía textual configuran el sistema de Núñez, con sutiles diferencias entre ambas ediciones de su glosa. Al fondo, de un lado, Servio y Beroaldo; y, de otro, Barbaro y Poliziano proporcionan algunas claves de la tensión entre modelos en proceso de constitución.

Palabras Clave: Juan de Mena. Laberinto. Hernán Núñez de Toledo. Crítica textual. Humanismo

\section{HERNÁN NÚÑEZ IN FRONT OF THE TEXT OF THE LABERINTO: ELEMENTS of ANCIENT AND Humanistic ECDOTICS}

\begin{abstract}
The two versions of Hernán Núñez's edition of and commentary on Juan de Mena's Laberinto illustrate a crossroads in humanist philology, between the scholiasts of Late Antiquity and a more modern evolution of the model. Núñez's system (which has subtle differences between the two editions of his annotations) is determined by: the adoption of the printed vulgata as a base-text; the proportion of annotations given over to text-critical discussion and the formal presentation of variance; the preponderance of emendations ope ingenii over those ope codicum; and the use of sources as a textual guide. Meanwhile, in the background, Servius and Beroaldus, on the one hand, and Barbaro and Poliziano, provide keys to the evident tension felt between models which were still taking form.
\end{abstract}

KeYwords: Juan de Mena. Laberinto. Hernán Núñez de Toledo. Textual criticism. Humanism. 